\title{
Stochastic Control and Analysis of Two-node Tandem Communication Network Model with DBA and Binomial Bulk Arrivals with Phase Type Transmission
}

\author{
K.Srinivas Rao \\ Dept. of Statistics \\ Andhra University \\ University \\ Visakhapatnam, India
}

\author{
Nakka Thirupathi Rao Kuda.Nageswara Rao \\ Dept. of CS \& SE \\ Andhra University \\ Visakhapatnam, India
}

\author{
P.Srinivasa Rao \\ Dept. of CS\&SE \\ Andhra University \\ Visakhapatnam, India
}

\begin{abstract}
Communication Systems are governed by several random factors. In packetized communication systems, the system performance is controlled by arrival pattern and Transmission strategy. In this paper, we introduced and analyse a two node communication network with the assumption that the arrivals are characterized by compound binomial Poisson process. Here, it is further assumed that the Dynamic bandwidth Allocation strategy of transmission is adopted and the two nodes are connected in tandem with phase type transmission in each node. The system performance is analysed by deriving the explicit expressions for the performance measures and numerical illustrations. It is observed that the bulk arrival distribution parameters and Dynamic Bandwidth Allocation Strategy can reduce the delays in transmission and burstness of buffers. With suitable cost considerations the optimal operating policies of the network are also discussed. This network can approximate the performance parameters of the system more close to the reality at places like LAN, WAN, MAN and ATM scheduling.
\end{abstract}

\section{Keywords}

Stochastic control, performance evaluation, tandem communication network, compound binomial Poisson process

\section{INTRODUCTION}

Generally the analysis of communication system is mainly concerned with the problem of data/voice transmission, packetization, channel capacity assignment, routing, statistical multiplexing, controlling the delay, resource allocation etc. For efficient and accurate prediction of performance measures it is needed to incorporate all these factors while building the communication network models. William Cock and Charles Wheatstone [12] (1939) are first people to introduce the mathematical theory of communication. Thereafter in 1948 a significant process was made in communication systems modelling [1, 2] (IEEE Communication society, (2002)).

Under variable load conditions, conducting laboratory experiments is highly complex and time consuming. The communication network models were developed and analysed for efficient design and evaluation of communication networks, with various assumptions on constituent processes like arrival process, service process, flow control mechanisms, allocation, routing etc,. Packet switching gives better utilization over circuit or message switching which yields relatively shorter delay this improves QOS. Statistical multiplexing of communication network can reduce the delay in packet switching. Several teleprocessing applications are mixed with dynamic engineering skills and statistical multiplexing (Gaujal and Hyon [3, 4] (2002), Parathasarathy et al [6, 7] (2001), Srinivasa Rao et al (2000)).
One of the most important considerations of communication network is the development of congestion control strategies. Usually bit dropping method is employed for congestion control. The idea of bit dropping is to discard certain portion of the traffic such as least significant bits in order to reduce the load in the transmission lines, while maintaining satisfactory quality of service to the end user, whenever there is congestion in buffers. Bit dropping method can be classified as input bit dropping (IBD) and output bit dropping (OBD) respectively (Kin K Leung [6] (2002)). In IBD bits may be dropped when the packets are placed in queue waiting for transmission. In contrast to IBD, bits are possibly discarded in OBD only from a packet being transmitted over the channel. This implies fluctuations in voice quality due to dynamically varying bit rate during a cell transmission. To maintain voice quality and to reduce the congestion in buffers the dynamic bandwidth allocation is evolved as an alternative and efficient control strategy over bit dropping or flow control strategies (Sriram K [7] (1993), Suresh Varma et al (1997), Padmavathi et al [9] (2009), Nageswara Rao et al [8] (2010)). In dynamic bandwidth allocation, a large portion of the utilized bandwidth is utilized by changing the transmission rate of packets depending on the content of the buffer connected to it. Much work has been reported recently regarding communication network model with dynamic bandwidth allocation (Stanislav Angelov (2009), Sriram K [15, 16] (1993)).

They assumed that the arrivals are single and follow a Poisson process. But, in packetized data voice transmission the messages are converted into a random number of packets and stored in buffer i.e., each arriving module is a batch of packets. Hence, the Poisson process may not able to analyse the network arrival stream correctly. So, Nageswara Rao et al [10], [11], (2010, 2011) have developed and analysed the communication networks with compound Poisson arrivals assuming the number of packets in each arriving module is random and follows a uniform distribution. But, in many practical situations, the number of packets in any arriving module may not be uniform and may follow a Binomial Distribution. Hence, in this paper we develop and analyse a communication network with dynamic bandwidth allocation having binomial bulk arrivals and modified phase type transmission for monitoring and scheduling of the systems. Using the difference differential equations, the joint probability generating function of the number of packets in each buffer is derived. The network behaviour is analysed by deriving explicit expressions for the average content of the buffers, mean delay in transmission, throughput of nodes, utilization of the transmitters etc,. The sensitivity of the model is analysed with respect to the parameters through numerical illustrations. The optimal operating policies of the network are also derived 
with suitable cost considerations. This model is useful for scheduling the tele and satellite communications.

\section{QUEUING MODEL}

Consider a two-transmitter tandem communication network in which the messages arrive to the network are converted into a random number of packets. The arrival process of the messages is random and a number of packets $(\mathrm{X})$ that a message can be converted follows a binomial distribution with parameters $\mathrm{m}$ and $\mathrm{p}$ i.e., the arrival modules follows a compound Poisson binomial process with composite arrival rate $\alpha$. $\mathrm{E}(\mathrm{X})$, where $\alpha$ is the mean arrival rate of modules.

The probability mass function of the number of packets that a message can be converted is

$$
\mathrm{C}_{\mathrm{k}}=\frac{{ }^{\mathrm{m}} \mathrm{C}_{\mathrm{k}} \mathrm{p}^{\mathrm{k}}(1-\mathrm{p})^{\mathrm{m}-\mathrm{k}}}{1-(1-\mathrm{p})^{\mathrm{m}}} \mathrm{K}=1,2, \ldots . \mathrm{m} .0<\mathrm{p}<1,
$$

Consider a Communication network in which two nodes are in tandem and the messages arrive to the first node are converted into number of packets and stored in first buffer connected to the first node. After transmitting from the first node, the packets may forwarded to the second buffer which is connected to the second node for forward transmission with the probability $\theta$ or the packets may be terminated after the first node with the probability $(1-\theta)$. It is further assumed that the arrival of packets to the first buffer is in bulk with random batch size having the probability mass function $\{\mathrm{Ck}\}$. In both the nodes the transmission is carried with dynamic bandwidth allocation. i.e the transmission rate at each node is adjusted instantaneously depending upon the content of the buffer connected to it. This can be modeled by considering that the transmission rates are linearly dependent on the content of the buffers.

Here, it is assumed that the arrival of packets follows compound Poisson process with parameter $\alpha$ and the number of transmissions at nodes 1 and 2 also follow compound Poisson processes with parameters $\beta_{1}$ and $\beta_{2}$. The queue discipline is First-In-First-Out (FIFO). The schematic diagram representing the communication network model is shown in figure 1.

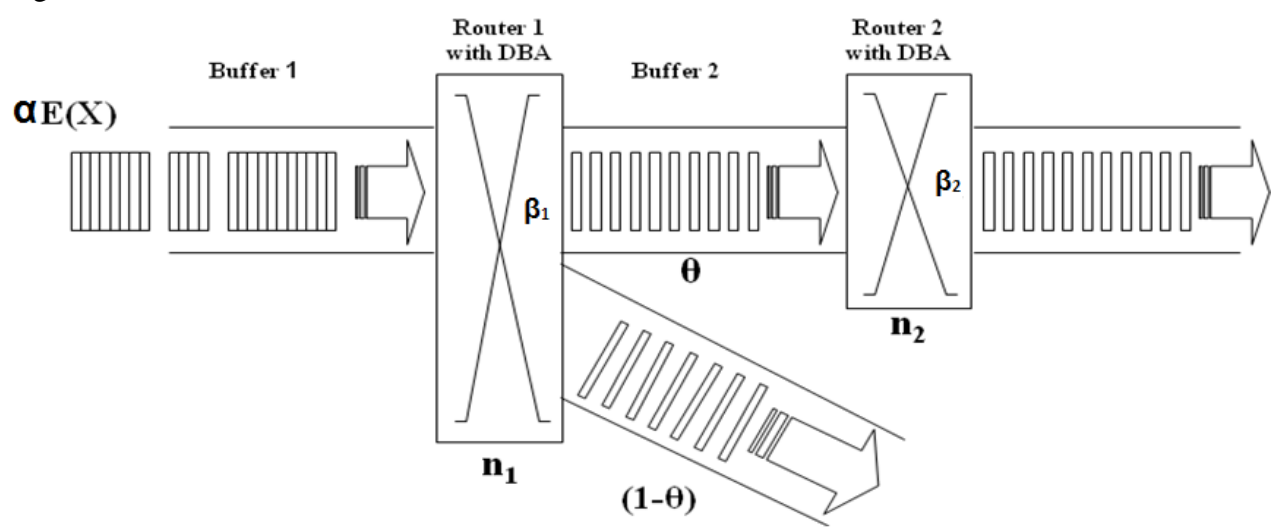

Figure 1: Communication network with dynamic bandwidth allocation and bulk arrivals having modified phase type transmission

$\mathrm{P}_{\mathrm{n}_{1}, \mathrm{n}_{2}}(\mathrm{t})$ is the probability that there are $\mathbf{n}_{\mathbf{1}}$ packets in the first buffer and $\mathbf{n}_{\mathbf{2}}$ packets in the second buffer at time t. With this structure, the difference - differential equations of the Communication network are

$$
\begin{aligned}
\frac{\partial \mathrm{P}_{\mathrm{n}_{1}, \mathrm{n}_{2}}(\mathrm{t})}{\partial \mathrm{t}} & =-\left(\alpha+\mathrm{n}_{1} \beta_{1}+\mathrm{n}_{2} \beta_{2}\right) \mathrm{P}_{\mathrm{n}_{1}, \mathrm{n}_{2}}(\mathrm{t})+\left(\mathrm{n}_{1}+1\right)(1-\theta) \beta_{1} \mathrm{P}_{\mathrm{n}_{1}+1, \mathrm{n}_{2}}(\mathrm{t}) \\
& +\left(\mathrm{n}_{1}+1\right) \theta \beta_{1} \mathrm{P}_{\mathrm{n}_{1}+1, \mathrm{n}_{2}-1}(\mathrm{t})+\left(\mathrm{n}_{2}+1\right) \beta_{2} \mathrm{P}_{\mathrm{n}_{1}, \mathrm{n}_{2}+1}(\mathrm{t})+\alpha\left[\sum_{\mathrm{i}=1}^{\mathrm{n}_{1}} \mathrm{P}_{\mathrm{n}_{1}-\mathrm{i}, \mathrm{n}_{2}}(\mathrm{t}) \frac{{ }^{\mathrm{m}} \mathrm{C}_{\mathrm{k}} \mathrm{p}^{\mathrm{k}}(1-\mathrm{p})^{\mathrm{m}-\mathrm{k}}}{1-(1-\mathrm{p})^{\mathrm{m}}}\right]
\end{aligned}
$$

$$
\begin{aligned}
& \frac{\partial \mathrm{P}_{\mathrm{n}_{1}, 0}(\mathrm{t})}{\partial \mathrm{t}}=-\left(\alpha+\mathrm{n}_{1} \beta_{1}\right) \mathrm{P}_{\mathrm{n}_{1}, 0}(\mathrm{t})+\left(\mathrm{n}_{1}+1\right)(1-\theta) \beta_{1} \mathrm{P}_{\mathrm{n}_{1}+1,0}(\mathrm{t})+ \\
& \beta_{2} \mathrm{P}_{\mathrm{n}_{1}, 1}(\mathrm{t})+\alpha\left[\sum_{\mathrm{i}=1}^{\mathrm{n}_{1}} \mathrm{P}_{\mathrm{n}_{1}-\mathrm{i}, 0}(\mathrm{t}) \frac{{ }^{\mathrm{m}} \mathrm{C}_{\mathrm{k}} \mathrm{p}^{\mathrm{k}}(1-\mathrm{p})^{\mathrm{m}-\mathrm{k}}}{1-(1-\mathrm{p})^{\mathrm{m}}}\right]
\end{aligned}
$$$$
\frac{\partial \mathrm{P}_{0, \mathrm{n}_{2}}(\mathrm{t})}{\partial \mathrm{t}}=-\left(\alpha+\mathrm{n}_{2} \beta_{2}\right) \mathrm{P}_{0, \mathrm{n}_{2}}(\mathrm{t})+(1-\theta) \beta_{1} \mathrm{P}_{1, \mathrm{n}_{2}}(\mathrm{t})+
$$$$
\theta \beta_{1} \mathrm{P}_{1, \mathrm{n}_{2}-1}(\mathrm{t})+\left(\mathrm{n}_{2}+1\right) \beta_{2} \mathrm{P}_{0, \mathrm{n}_{2}+1}(\mathrm{t})
$$

$$
\frac{\partial \mathrm{P}_{0,0}(\mathrm{t})}{\partial \mathrm{t}}=-\alpha \mathrm{P}_{0,0}(\mathrm{t})+(1-\theta) \beta_{1} \mathrm{P}_{1,0}(\mathrm{t})+\beta_{2} \mathrm{P}_{0,1}(\mathrm{t})
$$

$$
\begin{aligned}
& \frac{\partial \mathrm{P}_{1,0}(\mathrm{t})}{\partial \mathrm{t}}=-\left(\alpha+\beta_{1}\right) \mathrm{P}_{1,0}(\mathrm{t})+2(1-\theta) \beta_{1} \mathrm{P}_{2,0}(\mathrm{t})+\beta_{2} \mathrm{P}_{1,1}(\mathrm{t})+\alpha \mathrm{P}_{0,0}(\mathrm{t}) \mathrm{C}_{1} \\
& \frac{\partial \mathrm{P}_{0,1}(\mathrm{t})}{\partial \mathrm{t}}=-\left(\alpha+\beta_{2}\right) \mathrm{P}_{0,1}(\mathrm{t})+(1-\theta) \beta_{1} \mathrm{P}_{1,1}(\mathrm{t})+\theta \beta_{1} \mathrm{P}_{1,0}(\mathrm{t})+2 \beta_{2} \mathrm{P}_{0,2}(\mathrm{t})
\end{aligned}
$$

With initial conditions

$$
\mathrm{P}_{00}(0)=1 ; \mathrm{P}_{\mathrm{n}_{1}, \mathrm{n}_{2}}(0)=0 \text { for } \mathrm{n}_{1}, \mathrm{n}_{2}>0
$$

$\mathrm{P}\left(\mathrm{z}_{1}, \mathrm{Z}_{2} ; \mathrm{t}\right)$ denote the joint probability generating function of $\mathrm{P}_{\mathrm{n} 1, \mathrm{n} 2}(\mathrm{t})$ and $\mathrm{C}(\mathrm{Z})$ be the probability generating function of bulk arrivals. Then 


$$
\begin{gathered}
\mathrm{P}\left(\mathrm{z}_{1}, \mathrm{z}_{2} ; \mathrm{t}\right)=\sum_{\mathrm{n}_{1}=0}^{\infty} \sum_{\mathrm{n}_{2}=0}^{\infty} \mathrm{Z}_{1}^{\mathrm{n}_{1}} \mathrm{Z}_{2}^{\mathrm{n}_{2}} \mathrm{P}_{\mathrm{n}_{1}, \mathrm{n}_{2}}(\mathrm{t}) \\
\mathrm{C}(\mathrm{Z})=\sum_{\mathrm{k}=1}^{\mathrm{m}} \frac{{ }^{\mathrm{m}} \mathrm{C}_{\mathrm{k}} \mathrm{p}^{\mathrm{k}}(1-\mathrm{p})^{\mathrm{m}-\mathrm{k}}}{1-(1-\mathrm{p})^{\mathrm{m}}} \mathrm{Z}^{\mathrm{k}}
\end{gathered}
$$

Multiplying the equations (1) to (7) with corresponding $\mathrm{Z}_{1}^{\mathrm{n}_{1}}, \mathrm{Z}_{2}^{\mathrm{n}_{2}}$ and summing overall $\mathrm{n}_{1}=0,1,2,3, \ldots$ and $\mathrm{n}_{2}=0,1,2,3, \ldots$ one can get

$$
\begin{aligned}
& \sum_{\mathrm{n}_{1}=\mathrm{n}_{2}=1}^{\infty} \sum_{\partial}^{\infty} \frac{\partial}{\partial \mathrm{t}} \mathrm{P}_{\mathrm{n}_{1} \mathrm{n}_{2}}(\mathrm{t}) \mathrm{Z}_{1}^{\mathrm{n}_{1}} \mathrm{Z}_{2}^{\mathrm{n}_{2}}=-\left[\sum_{\mathrm{n}_{1}=0}^{\infty} \sum_{\mathrm{n}_{2}=0}^{\infty}\left(\alpha+\mathrm{n}_{1}(1-\theta) \beta_{1}+\mathrm{n}_{1} \theta \beta_{1}+\mathrm{n}_{2} \beta_{2}\right) \mathrm{P}_{\mathrm{n}_{1}, \mathrm{n}_{2}}(\mathrm{t}) \cdot \mathrm{Z}_{1}^{\mathrm{n}_{1}} Z_{2}^{\mathrm{n}_{2}}\right] \\
& +\sum_{\mathrm{n}_{1}=0}^{\infty} \sum_{\mathrm{n}_{2}=0}^{\infty}\left(\mathrm{n}_{1}+1\right)(1-\theta) \beta_{1} \mathrm{P}_{\mathrm{n}_{1}+1, \mathrm{n}_{2}}(\mathrm{t}) \cdot \mathrm{Z}_{1}^{\mathrm{n}_{1}} \mathrm{Z}_{2}^{\mathrm{n}_{2}}+ \\
& \sum_{\mathrm{n}_{1}=0 \mathrm{n}_{2}=0}^{\infty} \sum^{\infty}\left(\mathrm{n}_{1}+1\right) \theta \beta_{1} \mathrm{P}_{\mathrm{n}_{1}+1, \mathrm{n}_{2}-1}(\mathrm{t}) \cdot \mathrm{Z}_{1}^{\mathrm{n}_{1}} \mathrm{Z}_{2}^{\mathrm{n}_{2}} \\
& +\sum_{\mathrm{n}_{1}=0 \mathrm{n}_{2}=0}^{\infty} \sum_{2}^{\infty}\left(\mathrm{n}_{2}+1\right) \beta_{2} \mathrm{P}_{\mathrm{n}_{1}, \mathrm{n}_{2}+1}(\mathrm{t}) \cdot \mathrm{Z}_{1}^{\mathrm{n}_{1}} Z_{2}^{\mathrm{n}_{2}}+ \\
& \sum_{\mathrm{n}_{1}=1}^{\infty} \sum_{\mathrm{n}_{2}=1}^{\infty}\left[\alpha \sum_{\mathrm{k}=1}^{\mathrm{m}} \mathrm{P}_{\mathrm{n}_{1}-\mathrm{i}, \mathrm{n}_{2}}(\mathrm{t}) \cdot \frac{{ }^{\mathrm{m}} \mathrm{C}_{\mathrm{k}} \mathrm{p}^{\mathrm{k}}(1-\mathrm{p})^{\mathrm{m}-\mathrm{k}}}{1-(1-\mathrm{p})^{\mathrm{m}}}\right] \mathrm{Z}_{1}^{\mathrm{n}_{1}} \mathrm{Z}_{2}^{\mathrm{n}_{2}}
\end{aligned}
$$

After simplification, we have

$$
\begin{aligned}
& \frac{\partial \mathrm{P}\left(\mathrm{Z}_{1}, \mathrm{Z}_{2}, \mathrm{t}\right)}{\partial \mathrm{t}}=\left[\alpha\left(\mathrm{C}\left(\mathrm{Z}_{1}\right)-1\right)\right] \mathrm{P}\left(\mathrm{Z}_{1}, \mathrm{Z}_{2}, \mathrm{t}\right)+\left[-\beta_{1} \mathrm{Z}_{1}+\theta \beta_{1} \mathrm{Z}_{2}+(1-\theta) \beta_{1}\right] . \\
& \frac{\partial \mathrm{P}\left(\mathrm{Z}_{1} \mathrm{Z}_{2} ; \mathrm{t}\right)}{\partial \mathrm{Z}_{1}}+\left[\beta_{2}\left(1-\mathrm{Z}_{2}\right)\right] \frac{\partial \mathrm{P}\left(\mathrm{Z}_{1}, \mathrm{Z}_{2}, \mathrm{t}\right)}{\partial \mathrm{Z}_{2}}
\end{aligned}
$$

Rearrange the terms

$$
\begin{aligned}
& \left.\frac{\partial \mathrm{P}\left(\mathrm{Z}_{1}, \mathrm{Z}_{2} ; \mathrm{t}\right)}{\partial \mathrm{t}}-\left[\beta_{1} \mathrm{Z}_{1}+\theta \beta_{1} \mathrm{Z}_{2}+(1-\theta) \beta_{1}\right)\right] \cdot \frac{\partial \mathrm{P}\left(\mathrm{Z}_{1}, \mathrm{Z}_{2}, \mathrm{t}\right)}{\partial \mathbf{Z}_{1}}- \\
& {\left[\beta_{2}\left(1-\mathrm{Z}_{2}\right)\right] \frac{\partial \mathrm{P}\left(\mathrm{Z}_{1}, \mathrm{Z}_{2}, \mathrm{t}\right)}{\partial \mathbf{Z}_{2}}=\left[\alpha\left(\mathrm{C}\left(\mathrm{Z}_{1}\right)-1\right)\right] \mathrm{P}\left(\mathrm{Z}_{1}, \mathrm{Z}_{2} ; \mathrm{t}\right)}
\end{aligned}
$$

Using the Lagrangian's method, the auxiliary equations of the equation (9) are

$$
\frac{\mathrm{dt}}{1}=\frac{-\mathrm{dZ} \mathrm{Z}_{1}}{\left[-\beta_{1} \mathrm{Z}_{1}+\theta \beta_{1} \mathrm{Z}_{2}+(1-\theta)\right]}=\frac{-\mathrm{dZ} \mathrm{Z}_{2}}{\beta_{2}\left(1-\mathrm{Z}_{2}\right)}=\frac{\mathrm{dP}\left(\mathrm{Z}_{1}, \mathrm{Z}_{2}, \mathrm{t}\right)}{\left[\alpha\left(\mathrm{C}\left(\mathrm{Z}_{1}\right)-1\right)\right] \mathrm{P}\left(\mathrm{Z}_{1}, \mathrm{Z}_{2}, \mathrm{t}\right)}
$$

Solving the equations (10), one can get

$$
\begin{aligned}
& \mathbf{u}=\left(Z_{2}-\mathbf{1}\right) \mathrm{e}^{-\beta_{2} \mathbf{t}} \\
& \mathbf{v}=\left[\left(Z_{1}-1\right)+\frac{\theta \beta_{1}}{\beta_{2}-\beta_{1}}\left(Z_{2}-1\right)\right] \mathrm{e}^{-\beta_{1} \mathrm{t}}
\end{aligned}
$$

and

$$
\begin{aligned}
& \mathrm{w}=\mathrm{P}\left(\mathrm{Z}_{1}, Z_{2} ; \mathrm{t}\right) \cdot \exp \\
& {\left[-\alpha \sum_{\mathrm{k}=1}^{\mathrm{m}} \sum_{\mathrm{r}=1}^{\mathrm{k}} \sum_{\mathrm{J}=0}^{\mathrm{r}}(-1)^{2 \mathrm{r}-\mathrm{J}} \frac{{ }^{\mathrm{m}} \mathrm{C}_{\mathrm{k}} \mathrm{p}^{\mathrm{k}}(1-\mathrm{p})^{\mathrm{m}-\mathrm{k}}}{1-(1-\mathrm{p})^{\mathrm{m}}}\left({ }^{\mathrm{k}} \mathrm{C}_{\mathrm{r}}\right)\left({ }^{\mathrm{r}} \mathrm{C}_{\mathrm{J}}\right)\left(\frac{\theta \beta_{1}}{\beta_{2}-\beta_{1}}\right)^{\mathrm{J}} \mathrm{u}^{\mathrm{J}} \mathrm{v}^{(\mathrm{r}-\mathrm{J})} \frac{\mathrm{e}^{\left[\mathrm{J} \beta_{2}+(\mathrm{r}-\mathrm{J}) \beta_{1}\right] \mathrm{t}}}{\mathrm{J} \beta_{2}+(\mathrm{r}-\mathrm{J}) \beta_{1}}\right]}
\end{aligned}
$$

Where, $\mathbf{u}$ and $\mathbf{v}$ are as given in (11) and (12) respectively $\mathbf{u}, \mathbf{v}$ and $\mathbf{w}$ are arbitrary integral constants.

Therefore

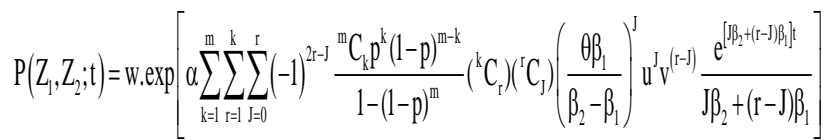

Substituting the value of ' $w$ ' one can get

$P\left(Z_{1}, Z_{2} ; t\right)=\left(\exp \left[-\alpha \sum_{k=1}^{m} \sum_{r=1}^{k} \sum_{J=0}^{r}(-1)^{2 r-J} \frac{{ }^{m} C_{k} p^{k}(1-p)^{m-k}}{1-(1-p)^{m}}\left({ }^{k} C_{r}\right)\left({ }^{r} C_{J}\right)\left(\frac{\theta \beta_{1}}{\beta_{2}-\beta_{1}}\right)^{j} u^{J} v^{(r-J)} \frac{1}{J \beta_{2}+(r-J) \beta_{1}}\right]\right)$.

$\left(\exp \left[\alpha \sum_{\mathrm{k}=1}^{\mathrm{m}} \sum_{\mathrm{r}=1}^{\mathrm{k}} \sum_{\mathrm{J}=0}^{\mathrm{r}}(-1)^{2 \mathrm{r}-\mathrm{J}} \frac{{ }^{\mathrm{m}} \mathrm{C}_{\mathrm{k}} \mathrm{p}^{\mathrm{k}}(1-\mathrm{p})^{\mathrm{m}-\mathrm{k}}}{1-(1-\mathrm{p})^{\mathrm{m}}}\left({ }^{\mathrm{k}} \mathrm{C}_{\mathrm{r}}\right)\left({ }^{\mathrm{r}} \mathrm{C}_{\mathrm{J}}\right)\left(\frac{\theta \beta_{1}}{\beta_{2}-\beta_{1}}\right)^{\mathrm{J}} \mathrm{u}^{\mathrm{J}} \mathrm{v}^{(\mathrm{r}-\mathrm{J})} \frac{\mathrm{e}^{\left[\mathrm{J} \beta_{2}+(\mathrm{r}-\mathrm{J}) \beta_{\mathrm{j}}\right] \mathrm{t}}}{\mathrm{J} \beta_{2}+(\mathrm{r}-\mathrm{J}) \beta_{1}}\right]\right)$

This implies

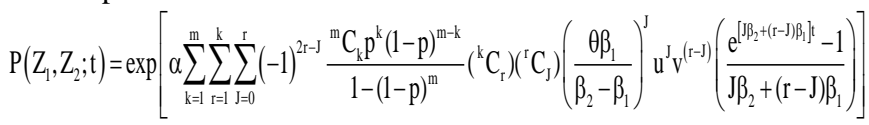

Substituting the values of $\mathbf{u}$ and $\mathbf{v}$ in the above equation and simplifying, one can get the joint probability generating function of the number of packets in the first node and second node as

$$
\begin{aligned}
& \mathrm{P}\left(\mathrm{Z}_{1}, \mathrm{Z}_{2}, \mathrm{t}\right)=\exp \left[\alpha \sum_{\mathrm{k}=1}^{\mathrm{m}} \sum_{\mathrm{r}=1}^{\mathrm{k}} \sum_{\mathrm{J}=0}^{\mathrm{r}}(-1)^{2 \mathrm{r}-\mathrm{J}} \frac{{ }^{\mathrm{m}} \mathrm{C}_{\mathrm{k}} \mathrm{p}^{\mathrm{k}}(1-\mathrm{p})^{\mathrm{m}-\mathrm{k}}}{1-(1-\mathrm{p})^{\mathrm{m}}}\left({ }^{\mathrm{k}} \mathrm{C}_{\mathrm{r}}\right)\left({ }^{\mathrm{r}} \mathrm{C}_{\mathrm{J}}\right)\left(\frac{\theta \beta_{1}}{\beta_{2}-\beta_{1}}\right)^{\mathrm{J}}\right. \\
& \left.\left(\mathrm{Z}_{2}-1\right)^{\mathrm{J}}\left(\left(\mathrm{Z}_{1}-1\right)+\frac{\theta \beta_{1}\left(\mathrm{Z}_{2}-1\right)}{\beta_{2}-\beta_{1}}\right)^{\mathrm{r}-\mathrm{J}} \frac{\left(1-\mathrm{e}^{-\left[\mathrm{J} \beta_{2}+(\mathrm{r}-\mathrm{J}) \beta_{1}\right] \mathrm{t}}\right)}{\mathrm{J} \beta_{2}+(\mathrm{r}-\mathrm{J}) \beta_{1}}\right]
\end{aligned}
$$

\section{PERFORMANCE MEASURES OF THE NETWORK}

In this section, we derive and analyze the performance measures of the communication network under transient state. From equations (14), the joint probability generating function of the number of packets in both the buffers is

$$
\begin{aligned}
& P\left(Z_{1}, Z_{2}, t\right)=\exp \left[\alpha \sum_{\mathrm{k}=1 \mathrm{r}=1 \mathrm{~J}=0}^{\mathrm{k}} \sum^{\mathrm{r}}(-1)^{2 \mathrm{r}-\mathrm{J}} \frac{{ }^{\mathrm{m}} \mathrm{C}_{\mathrm{k}} \mathrm{p}^{\mathrm{k}}(1-\mathrm{p})^{\mathrm{m}-\mathrm{k}}}{1-(1-\mathrm{p})^{\mathrm{m}}}\left({ }^{\mathrm{k}} \mathrm{C}_{\mathrm{r}}\right)\left({ }^{\mathrm{r}} \mathrm{C}_{\mathrm{J}}\right)\left(\frac{\theta \beta_{1}}{\beta_{2}-\beta_{1}}\right)^{\mathrm{J}}\right. \\
& \left.\left(\mathrm{Z}_{2}-1\right)^{\mathrm{J}}\left(\left(\mathrm{Z}_{1}-1\right)+\frac{\theta \beta_{1}\left(\mathrm{Z}_{2}-1\right)}{\beta_{2}-\beta_{1}}\right)^{\mathrm{r}-\mathrm{J}} \frac{\left(1-\mathrm{e}^{-\left[\mathrm{J} \beta_{2}+(\mathrm{r}-\mathrm{J}) \beta_{1}\right] \mathrm{t}}\right)}{\mathrm{J} \beta_{2}+(\mathrm{r}-\mathrm{J}) \beta_{1}}\right]
\end{aligned}
$$

Taking $\mathrm{Z}_{2}=1$, we get the probability generating function of the first buffer size distribution as

$\mathrm{P}\left(\mathrm{Z}_{1}, \mathrm{t}\right)=\exp \left[\alpha \sum_{\mathrm{k}=1}^{\mathrm{m}} \sum_{\mathrm{r}=1}^{\mathrm{k}} \frac{{ }^{\mathrm{m}} \mathrm{C}_{\mathrm{k}} \mathrm{p}^{\mathrm{k}}(1-\mathrm{p})^{\mathrm{m}-\mathrm{k}}}{1-(1-\mathrm{p})^{\mathrm{m}}}{ }^{\mathrm{k}} \mathrm{C}_{\mathrm{r}}\left(\mathrm{Z}_{1}-1\right)^{\mathrm{r}} \frac{\left(1-\mathrm{e}^{-\mathrm{r} \beta_{1} \mathrm{t}}\right)}{\mathrm{r} \beta_{1}}\right]$

Expanding the equation $\mathrm{P}\left(\mathrm{Z}_{1} \mathrm{t}\right)$ and collecting the constant terms, we get the probability that the first buffer is empty as

$\mathrm{p}_{0 .}(\mathrm{t})=\exp \left[\alpha \sum_{\mathrm{k}=1}^{\mathrm{m}} \sum_{\mathrm{r}=1}^{\mathrm{k}} \frac{{ }^{\mathrm{m}} \mathrm{C}_{\mathrm{k}} \mathrm{p}^{\mathrm{k}}(1-\mathrm{p})^{\mathrm{m}-\mathrm{k}}}{1-(1-\mathrm{p})^{\mathrm{m}}}{ }^{\mathrm{k}} \mathrm{C}_{\mathrm{r}}(-1)^{3 \mathrm{r}} \frac{\left(1-\mathrm{e}^{-\mathrm{r} \beta_{1} \mathrm{t}}\right)}{\mathrm{r} \beta_{1}}\right]$ 
The mean number of packets in the first buffer is

$\mathrm{L}_{1}=\frac{\alpha}{\beta_{1}}\left[\sum_{\mathrm{k}=1}^{\mathrm{m}} \frac{{ }^{\mathrm{m}} \mathrm{C}_{\mathrm{k}} \mathrm{p}^{\mathrm{k}}(1-\mathrm{p})^{\mathrm{m}-\mathrm{k}}}{1-(1-\mathrm{p})^{\mathrm{m}}} \cdot \mathrm{k}\left(1-\mathrm{e}^{-\beta_{1} \mathrm{t}}\right)\right]$

The utilization of the first node is

$\mathrm{U}_{1}=1-\mathrm{p}_{0 .}(\mathrm{t})$

$=1-\exp \left[\alpha \sum_{\mathrm{k}=1}^{\mathrm{m}} \sum_{\mathrm{r}=1}^{\mathrm{k}} \frac{{ }^{\mathrm{m}} \mathrm{C}_{\mathrm{k}} \mathrm{p}^{\mathrm{k}}(1-\mathrm{p})^{\mathrm{m}-\mathrm{k}}}{1-(1-\mathrm{p})^{\mathrm{m}}}{ }^{\mathrm{k}} \mathrm{C}_{\mathrm{r}}(-1)^{3 \mathrm{r}} \frac{\left(1-\mathrm{e}^{-\mathrm{r} \beta_{1} \mathrm{t}}\right)}{\mathrm{r} \beta_{1}}\right]$

The throughput of the first node is

$\mathrm{Thp}_{1}=\beta_{1} \cdot \mathrm{U}_{1}$

$=\beta_{1}\left[1-\exp \left[\alpha \sum_{\mathrm{k}=1}^{\mathrm{m}} \sum_{\mathrm{r}=1}^{\mathrm{k}} \frac{{ }^{\mathrm{m}} \mathrm{C}_{\mathrm{k}} \mathrm{p}^{\mathrm{k}}(1-\mathrm{p})^{\mathrm{m}-\mathrm{k}}}{1-(1-\mathrm{p})^{\mathrm{m}}}{ }^{\mathrm{k}} \mathrm{C}_{\mathrm{r}}(-1)^{3 \mathrm{r}} \frac{\left(1-\mathrm{e}^{-\mathrm{r} \beta_{1} \mathrm{t}}\right)}{\mathrm{r} \beta_{1}}\right]\right]$

The average delay in the first buffer is

$\mathrm{W}\left(\mathrm{N}_{1}\right)=\frac{\mathrm{L}_{1}}{\mathrm{Thp}_{1}}=\frac{\frac{\alpha}{\beta_{1}}\left[\sum_{\mathrm{k}=1}^{\mathrm{m}} \frac{{ }^{\mathrm{m}} \mathrm{C}_{\mathrm{k}} \mathrm{p}^{\mathrm{k}}(1-\mathrm{p})^{\mathrm{m}-\mathrm{k}}}{1-(1-\mathrm{p})^{\mathrm{m}}} \cdot \mathrm{k}\left(1-\mathrm{e}^{-\beta_{1} \mathrm{t}}\right)\right]}{\beta_{1}(1-\exp )\left[\alpha \sum_{\mathrm{k}=1}^{\mathrm{m}} \sum_{\mathrm{r}=1}^{\mathrm{k}} \frac{{ }^{\mathrm{m}} \mathrm{C}_{\mathrm{k}} \mathrm{p}^{\mathrm{k}}(1-\mathrm{p})^{\mathrm{m}-\mathrm{k}}}{1-(1-\mathrm{p})^{\mathrm{m}}}{ }^{\mathrm{k}} \mathrm{C}_{\mathrm{r}}(-1)^{3 \mathrm{r}} \frac{\left(1-\mathrm{e}^{\mathrm{r} \beta_{1} \mathrm{t}}\right)}{\mathrm{r} \beta_{1}}\right]}$

The variance of the number of packets in the first buffer is $\operatorname{Var}\left(\mathrm{N}_{1}\right)=\mathrm{E}\left[\mathrm{N}_{1}^{2}-\mathrm{N}_{1}\right]+\mathrm{E}\left[\mathrm{N}_{1}\right]-\left(\mathrm{E}\left[\mathrm{N}_{1}\right]\right)^{2}$

$=\frac{\alpha}{2 \beta_{1}}\left[\sum_{\mathrm{k}=1}^{\mathrm{m}} \frac{{ }^{\mathrm{m}} \mathrm{C}_{\mathrm{k}} \mathrm{p}^{\mathrm{k}}(1-\mathrm{p})^{\mathrm{m}-\mathrm{k}}}{1-(1-\mathrm{p})^{\mathrm{m}}} \mathrm{k}(\mathrm{k}-1)\left(1-\mathrm{e}^{-2 \beta_{1} \mathrm{t}}\right)\right]+\frac{\alpha}{\beta_{1}}\left[\sum_{\mathrm{k}=1}^{\mathrm{m}} \frac{{ }^{\mathrm{m}} \mathrm{C}_{\mathrm{k}} \mathrm{p}^{\mathrm{k}}(1-\mathrm{p})^{\mathrm{m}-\mathrm{k}}}{1-(1-\mathrm{p})^{\mathrm{m}}} \mathrm{k}\left(1-\mathrm{e}^{-\beta_{1} \mathrm{t}}\right)\right]$

The coefficient of variation of the number of packets in the first buffer is

$\operatorname{cv}\left(\mathrm{N}_{1}\right)=\frac{\sqrt{\mathrm{Var}\left(\mathrm{N}_{1}\right)}}{\mathrm{L}_{1}}$

Similarly, taking $Z_{1}=1$ in (14), we get the probability generating function of the second buffer size distribution

$P\left(Z_{2}, t\right)=\exp \left[a \sum_{k=1}^{m} \sum_{r=1}^{k} \sum_{J=0}^{r}(-1)^{2 r-J} \frac{{ }^{m} C_{k} p^{k}(1-p)^{m-k}}{1-(1-p)^{m}}\left({ }^{k} C_{r}\right)\left({ }^{r} C_{J}\right)\left(\frac{\theta \beta_{1}}{\beta_{2}-\beta_{1}}\right)^{r}\left(Z_{2}-1\right)^{r} \frac{\left.\left(1-e^{-\left[\beta_{2}+(r-J) / \beta\right]}\right] \mathrm{t}\right)}{J \beta_{2}+(r-J) \beta_{1}}\right]$

(24)

Expanding the equation $\mathrm{P}\left(\mathrm{Z}_{2}, \mathrm{t}\right)$ and collecting the constant terms, we get the probability that the second buffer is empty as

$\mathrm{p}_{.0}(\mathrm{t})=\exp \left[\alpha \sum_{\mathrm{k}=1}^{\mathrm{m}} \sum_{\mathrm{r}=1}^{\mathrm{k}} \sum_{\mathrm{J}=0}^{\mathrm{r}}(-1)^{3 \mathrm{r}-\mathrm{J}} \frac{{ }^{\mathrm{m}} \mathrm{C}_{\mathrm{k}} \mathrm{p}^{\mathrm{k}}(1-\mathrm{p})^{\mathrm{m}-\mathrm{k}}}{1-(1-\mathrm{p})^{\mathrm{m}}}\left({ }^{\mathrm{k}} \mathrm{C}_{\mathrm{r}}\right)\left({ }^{\mathrm{r}} \mathrm{C}_{\mathrm{J}}\right)\left(\frac{\theta \beta_{1}}{\beta_{2}-\beta_{1}}\right)^{\mathrm{r}} \frac{\left(1-\mathrm{e}^{\left.-\left[\mathrm{J} \beta_{2}+(\mathrm{r}-\mathrm{J}) \beta_{1}\right]\right]^{\mathrm{t}}}\right)}{\mathrm{J} \beta_{2}+(\mathrm{r}-\mathrm{J}) \beta_{1}}\right]$
$\mathrm{L}_{2}=\frac{\alpha \theta}{\beta_{2}}\left[\sum_{\mathrm{k}=1}^{\mathrm{m}} \frac{{ }^{\mathrm{m}} \mathrm{C}_{\mathrm{k}} \mathrm{p}^{\mathrm{k}}(1-\mathrm{p})^{\mathrm{m}-\mathrm{k}}}{1-(1-\mathrm{p})^{\mathrm{m}}} \cdot \mathrm{k}\left[\left(1-\mathrm{e}^{-\beta_{2} \mathrm{t}}\right)+\frac{\beta_{2}}{\beta_{2}-\beta_{1}}\left(\mathrm{e}^{-\beta_{2} \mathrm{t}}-\mathrm{e}^{-\beta_{1} \mathrm{t}}\right)\right]\right]$

The utilization of the second node is

$\mathrm{U}_{2}=1-\mathrm{p}_{.0}(\mathrm{t})$

$=1-\exp \left[\alpha \sum_{\mathrm{k}=1}^{\mathrm{m}} \sum_{\mathrm{r}=1}^{\mathrm{k}} \sum_{\mathrm{J}=0}^{\mathrm{r}}(-1)^{3 \mathrm{r}-\mathrm{J}} \frac{{ }^{\mathrm{m}} \mathrm{C}_{\mathrm{k}} \mathrm{p}^{\mathrm{k}}(1-\mathrm{p})^{\mathrm{m}-\mathrm{k}}}{1-(1-\mathrm{p})^{\mathrm{m}}}\left({ }^{\mathrm{k}} \mathrm{C}_{\mathrm{r}}\right)\left({ }^{\mathrm{r}} \mathrm{C}_{\mathrm{J}}\right)\left(\frac{\theta \beta_{1}}{\beta_{2}-\beta_{1}}\right)^{\mathrm{r}} \frac{\left(1-\mathrm{e}^{-\left[\mathrm{J} \beta_{2}+(\mathrm{r}-\mathrm{J}) \beta_{1}\right] \mathrm{t}}\right)}{\mathrm{J} \beta_{2}+(\mathrm{r}-\mathrm{J}) \beta_{1}}\right]$

The throughput of the second node is

$\mathrm{Thp}_{2}=\beta_{2} . \mathrm{U}_{2}$

$=\beta_{2}(1-\exp )\left[\alpha \sum_{\mathrm{k}=1 \mathrm{r}=1 \mathrm{~J}=0}^{\mathrm{m}} \sum^{\mathrm{k}} \sum^{\mathrm{r}}(-1)^{3 \mathrm{r}-\mathrm{J}} \frac{{ }^{\mathrm{m}} \mathrm{C}_{\mathrm{k}} \mathrm{p}^{\mathrm{k}}(1-\mathrm{p})^{\mathrm{m}-\mathrm{k}}}{1-(1-\mathrm{p})^{\mathrm{m}}}\left({ }^{\mathrm{k}} \mathrm{C}_{\mathrm{r}}\right)\left({ }^{\mathrm{r}} \mathrm{C}_{\mathrm{J}}\right)\left(\frac{\theta \beta_{1}}{\beta_{2}-\beta_{1}}\right)^{\mathrm{r}}\left(1-\frac{\left(-\mathrm{e}^{-\left[\mathrm{J} \beta_{2}+(\mathrm{r}-\mathrm{J}) \beta_{1}\right] \mathrm{t}}\right)}{\mathrm{J} \beta_{2}+(\mathrm{r}-\mathrm{J}) \beta_{1}}\right]\right.$

The average delay in the second buffer is

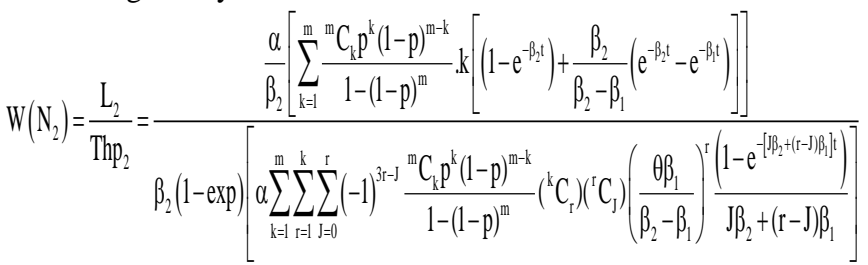

The variance of number of packets in the second buffer is

$$
\begin{aligned}
& \operatorname{Var}\left(\mathrm{N}_{2}\right)=\mathrm{E}\left[\mathrm{N}_{2}^{2}-\mathrm{N}_{2}\right]+\mathrm{E}\left[\mathrm{N}_{2}\right]-\left(\mathrm{E}\left[\mathrm{N}_{2}\right]\right)^{2} \\
& =\left\{\alpha\left(\sum_{k=1}^{m} \frac{{ }^{m} C_{k} p^{k}(1-p)^{m-k}}{1-(1-p)^{m}} \cdot k(k-1)\right)\left(\frac{\theta \beta_{1}}{\beta_{1}-\beta_{2}}\right)^{2}\left[\left(\frac{1-e^{-2 \beta_{1} t}}{2 \beta_{1}}\right)-2\left(\frac{1-e^{-\left(\beta_{1}+\beta_{2}\right) t}}{\beta_{1}+\beta_{2}}\right)+\left(\frac{1-e^{-2 \beta_{2} t}}{2 \beta_{2}}\right)\right]\right\} \\
& +\left\{\alpha \theta \sum_{\mathrm{k}=1}^{\mathrm{m}} \mathrm{k} \cdot \frac{{ }^{\mathrm{m}} \mathrm{C}_{\mathrm{k}} \mathrm{p}^{\mathrm{k}}(1-\mathrm{p})^{\mathrm{m}-\mathrm{k}}}{1-(1-\mathrm{p})^{\mathrm{m}}}\left[\left(\frac{1-\mathrm{e}^{-\beta_{2} \mathrm{t}}}{\beta_{2}}\right)-\left(\frac{\mathrm{e}^{-\beta_{2} \mathrm{t}}-\mathrm{e}^{-\beta_{1} \mathrm{t}}}{\beta_{1}-\beta_{2}}\right)\right]\right\}
\end{aligned}
$$

The coefficient of variation of the number of packets in the second buffer is

$$
\operatorname{cv}\left(\mathrm{N}_{2}\right)=\frac{\sqrt{\mathrm{V} \operatorname{ar}\left(\mathrm{N}_{2}\right)}}{\mathrm{L}_{2}}
$$

Expanding the equation (14) and collecting the constant terms, we get the probability that the network is empty as

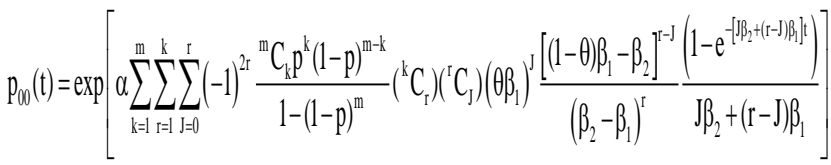


The mean number of packets in the network is

$$
\mathrm{L}_{\mathrm{N}}=\mathrm{L}_{1}+\mathrm{L}_{2}
$$

Where,

$\mathrm{L}_{1}$ is the mean number of packets in the first node

$\mathrm{L}_{2}$ is the mean number of packets in the second node

\section{PERFORMANCE EVALUATION OF THE NETWORK}

In this section, the performance of the proposed network is discussed through numerical illustration. Different values of the parameters are considered for bandwidth allocation and arrival of packets. After interacting with the technical staff at the Internet providing station, it is considered that the message arrival rate $(\alpha)$ varies from $1 \times 10^{4}$ messages/sec to $4 \times 10^{4}$ massages/sec. The number of packets that can be converted into a message varies from 1 to 30 depending on the length of the message. Hence, the number of arrivals of packets to the buffer are in batches of random size. The batch size is assumed to follow Binomial distribution with parameters $(m, p)$. After transmitter 1, the packets are forwarded to the second buffer connected to the second transmitter, with forward transmission rate $\left(\beta_{1}\right)$ varies from $1 \times 10^{4}$ packets/sec to $5 \times 10^{4}$ packets/sec. the packets leave the second transmitter with a transmission rate $\left(\beta_{2}\right)$ which varies from $1 \times 10^{4}$ packets/sec to $5 \times 10^{4}$ packets/sec. In both the nodes, dynamic bandwidth allocation is considered i.e. the transmission rate of each packet depends on the number of packets in the buffer connected to it at the instant. Since performance characteristics of the communication network are highly sensitive with respect to time, the transient behaviour of the model is studied through computing the performance measures with the following set of values for the model parameters:

$\mathrm{t}=0.1,0.2,0.3,0.4$ seconds

$\mathrm{m}=1,2,3,4$

$\mathrm{p}=0.1,0.2,0.3,0.4 \mathrm{xm}$

packets/sec)

$\alpha=1,2,3,4$ (with multiplication of $10^{4}$

$\theta=0.1,0.2,0.3,0.4$ (with multiplication of $10^{4}$ Packets/sec) packets/sec)

$\beta_{1}=1,2,3,4$ (with multiplication of $10^{4}$ packets/sec)

$\beta_{2}=5,6,7,8$ (with multiplication of $10^{4}$

From equations (21) to (31), the transmission rate of first transmitter and the transmission rate of second transmitter are computed for different values of $\mathrm{t}, \mathrm{m}, \mathrm{p}, \alpha, \theta, \beta_{1}, \beta_{2}$ and given in Table 1.The relationship between the parameters and the probability of emptiness are shown in figure 2 .

Table 1: Values of Network and Buffers Emptiness Probabilities of the Communication Network with Dynamic Bandwidth Allocation and Binomial Bulk Arrivals

\begin{tabular}{|r|r|r|r|r|r|r|r|r|r|}
\hline $\mathrm{t}$ & $\mathrm{m}$ & $\mathrm{p}$ & $\alpha$ & $\theta$ & $\beta_{1}$ & $\beta_{2}$ & $\mathrm{P}_{00}(\mathrm{t})$ & $\mathrm{P}_{0 .}(\mathrm{t})$ & $\mathrm{P}_{.0}(\mathrm{t})$ \\
\hline 0.1 & 2 & 0.3 & 2 & 0.5 & 4 & 8 & 0.745 & 0.844 & 0.984 \\
\hline 0.2 & 2 & 0.3 & 2 & 0.5 & 4 & 8 & 0.561 & 0.749 & 0.957 \\
\hline 0.3 & 2 & 0.3 & 2 & 0.5 & 4 & 8 & 0.516 & 0.690 & 0.932 \\
\hline 0.4 & 2 & 0.3 & 2 & 0.5 & 4 & 8 & 0.498 & 0.652 & 0.912 \\
\hline 0.2 & 1 & 0.3 & 2 & 0.5 & 4 & 8 & 0.654 & 0.759 & 0.963 \\
\hline 0.2 & 2 & 0.3 & 2 & 0.5 & 4 & 8 & 0.488 & 0.740 & 0.952 \\
\hline
\end{tabular}

\begin{tabular}{|l|l|l|l|l|l|l|l|l|r|}
\hline 0.2 & 3 & 0.3 & 2 & 0.5 & 4 & 8 & 0.305 & 0.724 & 0.940 \\
\hline 0.2 & 4 & 0.3 & 2 & 0.5 & 4 & 8 & 0.146 & 0.711 & 0.928 \\
\hline 0.2 & 2 & 0.1 & 2 & 0.5 & 4 & 8 & 0.624 & 0.756 & 0.9601 \\
\hline 0.2 & 2 & 0.2 & 2 & 0.5 & 4 & 8 & 0.593 & 0.753 & 0.959 \\
\hline 0.2 & 2 & 0.3 & 2 & 0.5 & 4 & 8 & 0.56 & 0.749 & 0.957 \\
\hline 0.2 & 2 & 0.4 & 2 & 0.5 & 4 & 8 & 0.525 & 0.745 & 0.955 \\
\hline 0.2 & 2 & 0.3 & 1 & 0.5 & 4 & 8 & 0.748 & 0.866 & 0.978 \\
\hline 0.2 & 2 & 0.3 & 2 & 0.5 & 4 & 8 & 0.560 & 0.749 & 0.957 \\
\hline 0.2 & 2 & 0.3 & 3 & 0.5 & 4 & 8 & 0.419 & 0.649 & 0.936 \\
\hline 0.2 & 2 & 0.3 & 4 & 0.5 & 4 & 8 & 0.313 & 0.561 & 0.916 \\
\hline 0.2 & 2 & 0.3 & 2 & 0.5 & 1 & 8 & 0.550 & 0.692 & 0.985 \\
\hline 0.2 & 2 & 0.3 & 2 & 0.5 & 2 & 8 & 0.560 & 0.712 & 0.975 \\
\hline 0.2 & 2 & 0.3 & 2 & 0.5 & 3 & 8 & 0.568 & 0.731 & 0.965 \\
\hline 0.2 & 2 & 0.3 & 2 & 0.5 & 4 & 8 & 0.574 & 0.749 & 0.957 \\
\hline 0.2 & 2 & 0.3 & 2 & 0.5 & 4 & 5 & 0.527 & 0.749 & 0.959 \\
\hline 0.2 & 2 & 0.3 & 2 & 0.5 & 4 & 6 & 0.537 & 0.749 & 0.952 \\
\hline 0.2 & 2 & 0.3 & 2 & 0.5 & 4 & 7 & 0.548 & 0.749 & 0.955 \\
\hline 0.2 & 2 & 0.3 & 2 & 0.5 & 4 & 8 & 0.560 & 0.749 & 0.957 \\
\hline 0.2 & 2 & 0.3 & 2 & 0.1 & 4 & 8 & 0.560 & 0.749 & 0.991 \\
\hline 0.2 & 2 & 0.3 & 2 & 0.2 & 4 & 8 & 0.528 & 0.749 & 0.982 \\
\hline 0.2 & 2 & 0.3 & 2 & 0.3 & 4 & 8 & 0.497 & 0.749 & 0.974 \\
\hline 0.2 & 2 & 0.3 & 2 & 0.4 & 4 & 8 & 0.466 & 0.749 & 0.965 \\
\hline
\end{tabular}

$*=$ Seconds, \#=Multiples of 10, 000 messages/seconds, $\$=$ Multiples of 10,000 packets/second

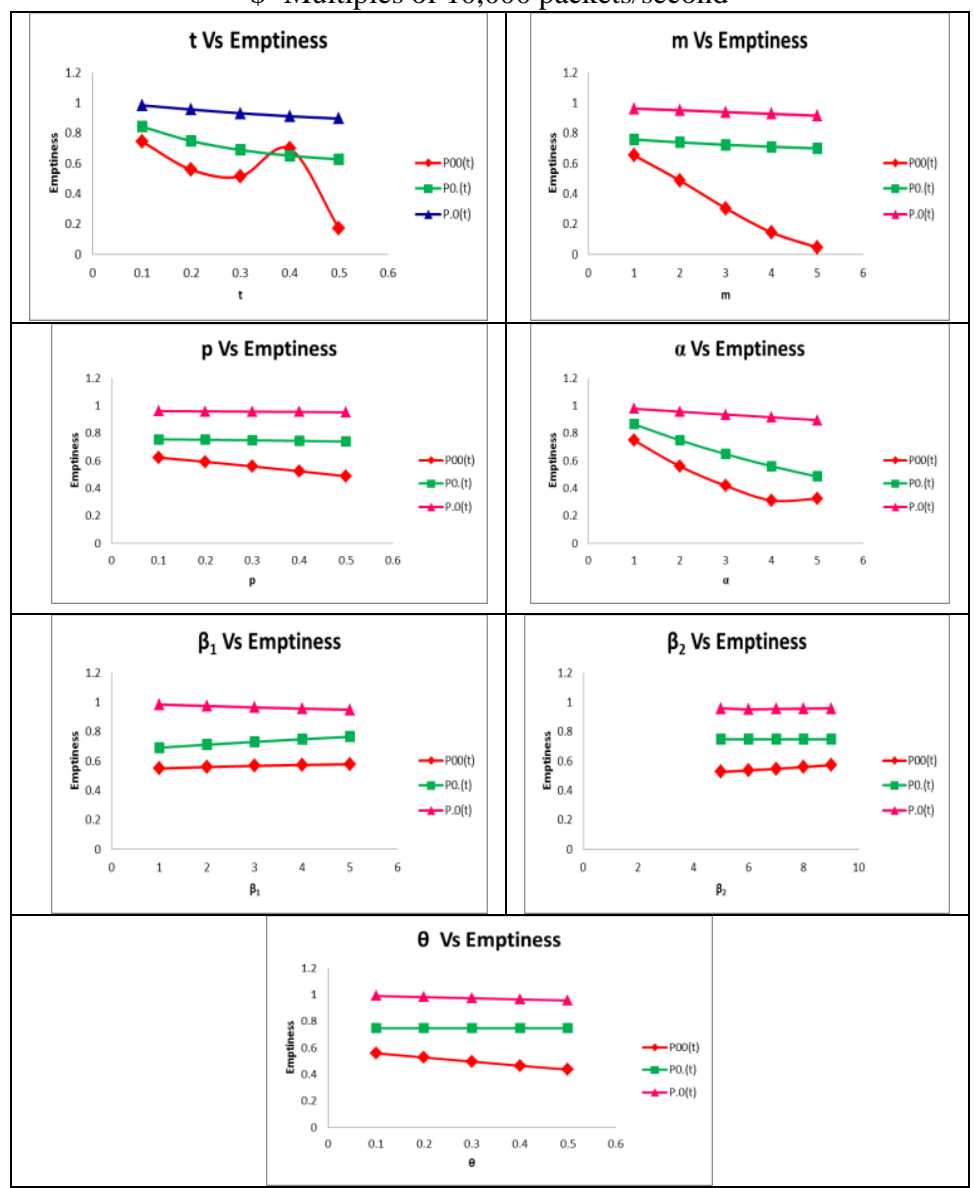

Figure 2: The relationship between probability of Emptiness and various parameters

It is observed that the probability of emptiness of the communication network and the two buffers are highly sensitive with respect to changes in time. As time (t) varies from 0.1 to 0.4 second, the probability of emptiness in the network reduces from 0.745 to 0.498 when other parameters are fixed at $(2,0.3,2,0.5,4,8)$ for $(\mathrm{m}, \mathrm{p}, \alpha, \theta$, $\beta_{1}, \beta_{2}$ ). Similarly, the probabilities of emptiness of the two buffers reduce from 0.844 to 0.652 and 0.984 to 0.912 for node 1 and node 2 respectively. The decrease in node 1 is 
more rapid when compared to node 2 . When the batch size distribution of number of packets a message can be converted (m) varies from 1 to 4 , the probability of emptiness of the network decreases from 0.654 to 0.146 when other parameters are fixed at $(0.2,0.3,2,0.5,4,8)$ for ( $\mathrm{t}, \mathrm{p}, \alpha, \theta, \beta_{1}, \beta_{2}$ ). The same phenomenon is observed with respect to the first and second nodes. The probabilities of emptiness of the first and second buffers decrease from 0.759 to 0.711 and 0.963 to 0.928 respectively. When the batch size distribution parameter (p) varies from 0.1 to 0.4 , the probability of emptiness of the network decreases from 0.624 to 0.525 when other parameters are fixed at $(0.2,2,2,0.5,4,8)$ for $(\mathrm{t}, \mathrm{m}, \alpha, \theta$, $\beta_{1}, \beta_{2}$ ). The same phenomenon is observed with respect to the first and second nodes. The probabilities of emptiness of the first and second buffers decrease from 0.756 to 0.745 and 0.960 to 0.955 respectively.

The influence of arrival of messages on system emptiness is also studied. As the arrival rate $(\alpha)$ varies from $1 \times 10^{4}$ messages/sec to $4 \times 10^{4}$ message/sec, the probability of emptiness of the network decreases from 0.748 to 0.313 when other parameters are fixed at $(0.2,2,0.3,0.5,4,8)$ for $\left(\mathrm{t}, \mathrm{m}, \mathrm{p}, \theta, \beta_{1}, \beta_{2}\right)$. The same phenomenon is observed with respect to the first and second nodes. This decline is more in first node and moderate in the second node. When the probability of packets forwarded $(\theta)$ varies from $0.1 \times 10^{4} \mathrm{packet} / \mathrm{sec}$ to $0.4 \times 10^{4} \mathrm{packet} / \mathrm{sec}$, the probability of emptiness of the network decreases from 0.560 to 0.466 and the first buffer remain unchanged as 0.749 and the probability of emptiness of the second buffer decreases from 0.991 to 0.965 when other parameters remain fixed at $(0.2,2,0.3,2,4,8)$ for $\left(\mathrm{t}, \mathrm{m}, \mathrm{p}, \alpha, \beta_{1}, \beta_{2}\right)$. When the transmission rate of first transmitter $\left(\beta_{1}\right)$ varies from $1 \times 10^{4}$ packet/sec to $4 \times 10^{4}$ packet/sec, the probability of emptiness of the network and the first buffer increases from 0.550 to 0.574 and 0.692 to 0.749 respectively and the probability of emptiness of the second buffer decreases from 0.985 to 0.957 when other parameters remain fixed at $(0.2,2,0.3,2,0.5,8)$ for $\left(\mathrm{t}, \mathrm{m}, \mathrm{p}, \alpha, \theta, \beta_{2}\right)$.

When the transmission rate of second transmitter $\left(\beta_{2}\right)$ varies from $5 \times 10^{4}$ packet/sec to $8 \times 10^{4}$ packet/sec, the probability of emptiness of the network and the second buffer increases from 0.527 to 0.560 and 0.951 to 0.957 respectively when other parameters remain fixed at $(0.2,2$, $0.3,2,0.5,4)$ for ( $\left.\mathrm{t}, \mathrm{m}, \mathrm{p}, \alpha, \theta, \beta_{1}\right)$. From the equations (19 to 26 and 27), the mean number of packets and the utilization of the network are computed for different values of $\mathrm{t}, \mathrm{m}, \mathrm{p}, \alpha, \theta, \beta_{1}, \beta_{2}$ and are given in Table 2 . The relationship between mean number of packets in the buffers, utilization of the nodes with the parameters $t, m$, $\mathrm{p}, \alpha, \theta, \beta_{1}, \beta_{2}$ is shown in figure 3 and figure 4 . It is observed that after 0.1 seconds, the first buffer is having on an average of 1940 packets, after 0.4 seconds it rapidly raised to an average of 4690 packets for fixed values of other parameters $(2,0.3,2,0.5,4,8)$ for $\left(\mathrm{m}, \mathrm{p}, \alpha, \theta, \beta_{1}, \beta_{2}\right)$. It is also observed that as time $(\mathrm{t})$ varies from 0.1 to 0.4 seconds, average content of the second buffer and the network increases from 0160 packets to 940 packets and from 210 to 5630 packets respectively.
Table 2: Values of mean number of packets and utilization of the communication network with dynamic bandwidth allocation and bulk arrivals

\begin{tabular}{|c|c|c|c|c|r|r|r|r|r|r|r|}
\hline $\mathrm{t}^{*}$ & $\mathrm{~m}$ & $\mathrm{p}$ & $\alpha \#$ & $\theta$ & $\beta_{1} \$$ & $\beta_{2} \$$ & $\mathrm{~L}_{1}$ & $\mathrm{U}_{1}$ & $\mathrm{~L}_{2}$ & $\mathrm{U}_{2}$ & Ln \\
\hline 0.1 & 2 & 0.3 & 2 & 0.5 & 4 & 8 & 0.194 & 0.156 & 0.016 & 0.016 & 0.021 \\
\hline 0.2 & 2 & 0.3 & 2 & 0.5 & 4 & 8 & 0.324 & 0.251 & 0.045 & 0.043 & 0.369 \\
\hline 0.3 & 2 & 0.3 & 2 & 0.5 & 4 & 8 & 0.411 & 0.310 & 0.072 & 0.068 & 0.483 \\
\hline 0.4 & 2 & 0.3 & 2 & 0.5 & 4 & 8 & 0.469 & 0.348 & 0.094 & 0.088 & 0.563 \\
\hline 0.2 & 5 & 0.3 & 2 & 0.5 & 4 & 8 & 0.275 & 0.241 & 0.038 & 0.037 & 0.313 \\
\hline 0.2 & 6 & 0.3 & 2 & 0.5 & 4 & 8 & 0.367 & 0.260 & 0.051 & 0.048 & 0.418 \\
\hline 0.2 & 7 & 0.3 & 2 & 0.5 & 4 & 8 & 0.472 & 0.276 & 0.065 & 0.060 & 0.537 \\
\hline 0.2 & 8 & 0.3 & 2 & 0.5 & 4 & 8 & 0.587 & 0.289 & 0.081 & 0.072 & 0.668 \\
\hline 0.2 & 2 & 0.1 & 2 & 0.5 & 4 & 8 & 0.290 & 0.244 & 0.040 & 0.039 & 0.330 \\
\hline 0.2 & 2 & 0.2 & 2 & 0.5 & 4 & 8 & 0.306 & 0.247 & 0.042 & 0.041 & 0.348 \\
\hline 0.2 & 2 & 0.3 & 2 & 0.5 & 4 & 8 & 0.324 & 0.251 & 0.045 & 0.043 & 0.364 \\
\hline 0.2 & 2 & 0.4 & 2 & 0.5 & 4 & 8 & 0.344 & 0.255 & 0.047 & 0.044 & 0.392 \\
\hline 0.2 & 2 & 0.3 & 1 & 0.5 & 4 & 8 & 0.162 & 0.134 & 0.022 & 0.022 & 0.184 \\
\hline 0.2 & 2 & 0.3 & 2 & 0.5 & 4 & 8 & 0.324 & 0.251 & 0.045 & 0.043 & 0.369 \\
\hline 0.2 & 2 & 0.3 & 3 & 0.5 & 4 & 8 & 0.486 & 0.351 & 0.067 & 0.064 & 0.553 \\
\hline 0.2 & 2 & 0.3 & 4 & 0.5 & 4 & 8 & 0.648 & 0.439 & 0.089 & 0.084 & 0.737 \\
\hline 0.2 & 2 & 0.3 & 2 & 0.5 & 1 & 8 & 0.427 & 0.308 & 0.014 & 0.014 & 0.440 \\
\hline 0.2 & 2 & 0.3 & 2 & 0.5 & 2 & 8 & 0.388 & 0.288 & 0.026 & 0.025 & 0.413 \\
\hline 0.2 & 2 & 0.3 & 2 & 0.5 & 3 & 8 & 0.354 & 0.269 & 0.036 & 0.035 & 0.390 \\
\hline 0.2 & 2 & 0.3 & 2 & 0.5 & 4 & 8 & 0.324 & 0.251 & 0.045 & 0.043 & 0.369 \\
\hline 0.2 & 2 & 0.3 & 2 & 0.5 & 4 & 1 & 0.324 & 0.251 & 0.053 & 0.051 & 0.377 \\
\hline 0.2 & 2 & 0.3 & 2 & 0.5 & 4 & 2 & 0.324 & 0.251 & 0.050 & 0.048 & 0.374 \\
\hline 0.2 & 2 & 0.3 & 2 & 0.5 & 4 & 3 & 0.324 & 0.251 & 0.047 & 0.045 & 0371 \\
\hline 0.2 & 2 & 0.3 & 2 & 0.5 & 4 & 4 & 0.324 & 0.251 & 0.045 & 0.043 & 0.371 \\
\hline 0.2 & 2 & 0.3 & 2 & 0.1 & 4 & 8 & 0.324 & 0.251 & 0.009 & 0.009 & 0.333 \\
\hline 0.2 & 2 & 0.3 & 2 & 0.2 & 4 & 8 & 0.324 & 0.251 & 0.018 & 0.018 & 0.342 \\
\hline 0.2 & 2 & 0.3 & 2 & 0.3 & 4 & 8 & 0.324 & 0.251 & 0.027 & 0.026 & 0.352 \\
\hline 0.2 & 2 & 0.3 & 2 & 0.4 & 4 & 8 & 0.324 & 0.251 & 0.036 & 0.035 & 0.361 \\
\hline
\end{tabular}

As the batch size distribution parameter $(\mathrm{m})$ varies from 5 to 8 , the first buffer values increases from 2750 packets to 5870 packets, the second buffer and the network average content increase from 380 packets to 810 packets and 3130 packets to 6680 packets. As the batch size distribution parameter $(\mathrm{p})$ varies from 0.1 to 0.4 , the first buffer value increases from 2900 packets to 3440 packets and the second buffer increases from 400 packets to 470 packets, network average content increases from 3300 packets to 3920 packets respectively when other parameters remain fixed.

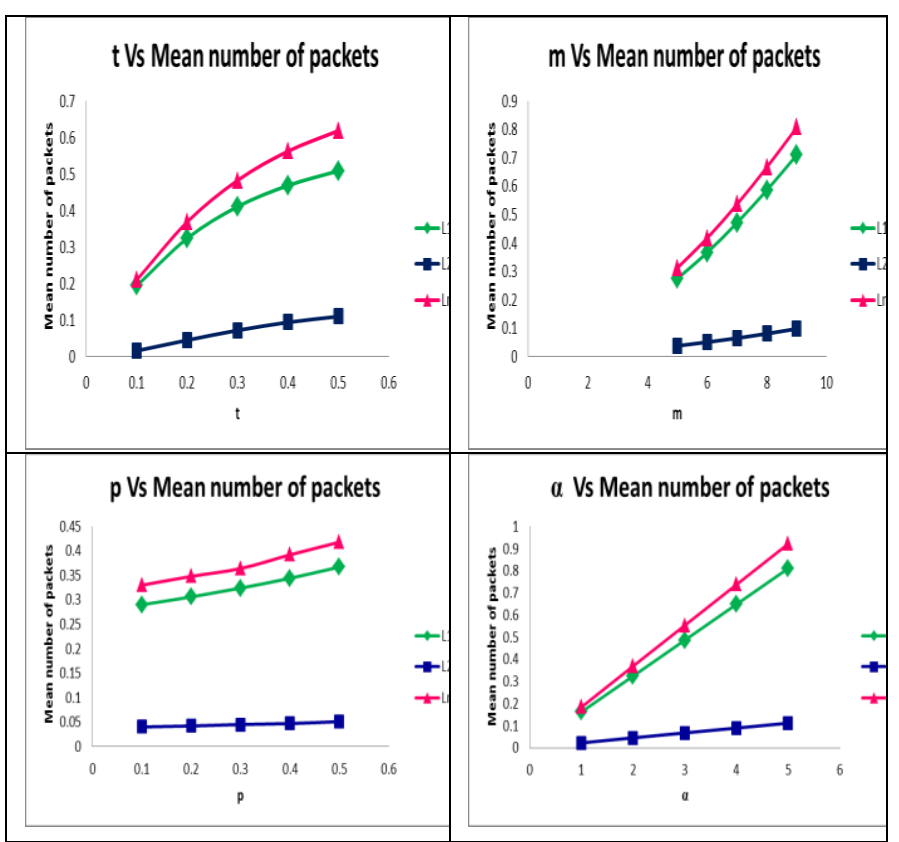




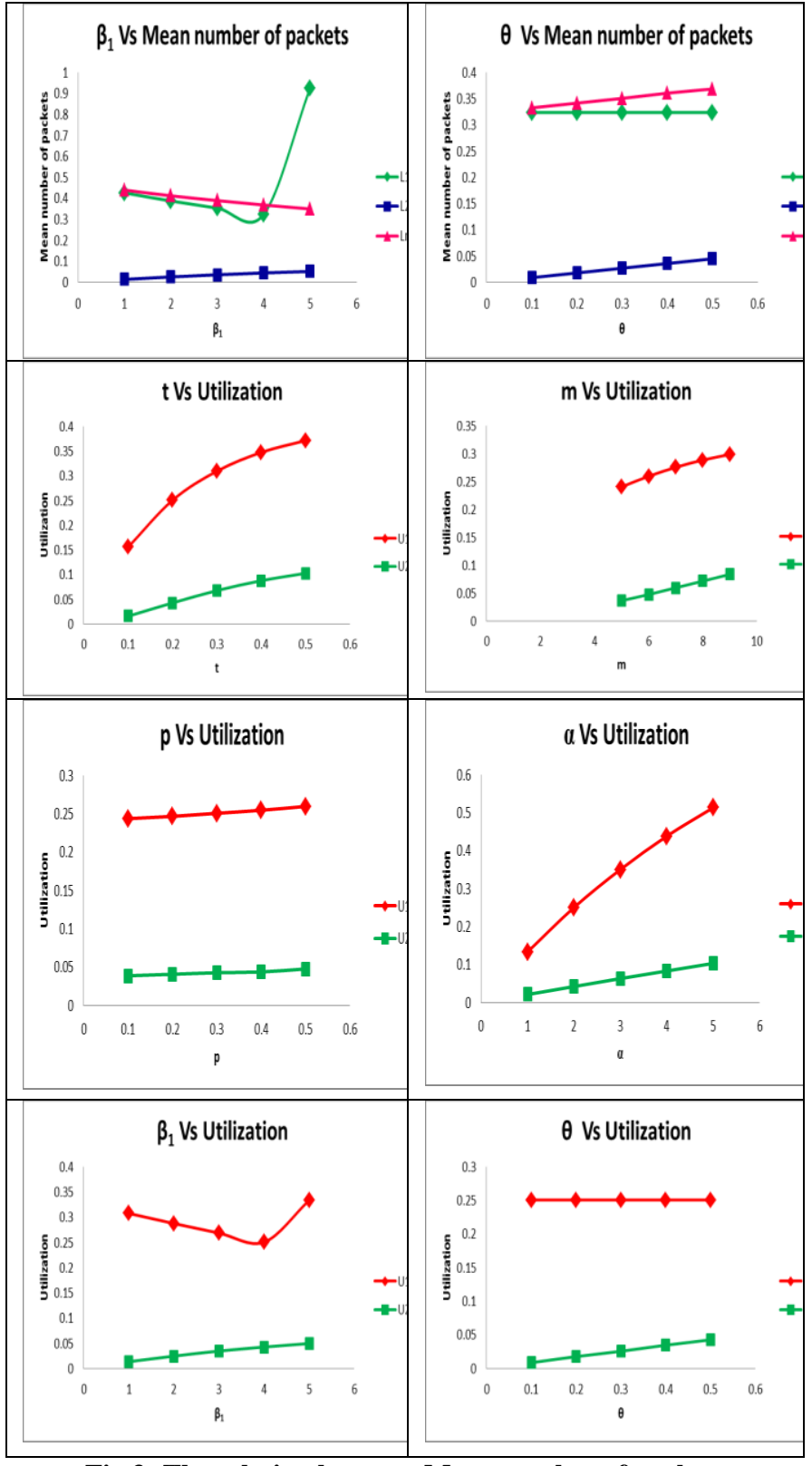

Fig 3: The relation between Mean number of packets and utilization for various parameters

As the arrival rate of messages $(\alpha)$ varies from $1 \times 10^{4}$ messages/sec to $4 \times 10^{4}$ messages/sec the first buffer, second buffer and the network average content increase from 1620 packets to 6480 packets, 220 packets to 890 packets and 1840 packets to 7370 packets respectively when other parameters remain fixed at $(0.2,2,0.3,0.5,4$, 8 ) for (t, $\left.\mathrm{m}, \mathrm{p}, \theta, \beta_{1}, \beta_{2}\right)$. As the transmission rate of first transmitter $\left(\beta_{1}\right)$ varies from $1 \times 10^{4}$ packets/sec to $4 \times 10^{4}$ packets/sec, the first buffer and the network average content decrease from 4270 packets to 3240 packets and from 4400 packets to 3690 packets, the second buffer average increases from 140 packets to 450 packets respectively when other parameters remain fixed at $(0.2,2$, $0.3,2,0.5,8)$ for $\left(\mathrm{t}, \mathrm{m}, \mathrm{p}, \alpha, \theta, \beta_{2}\right)$. As the transmission rate of second transmitter $\left(\beta_{2}\right)$ varies from $1 \times 10^{4}$ packets/sec to $4 \times 10^{4}$ packets/sec, the second buffer and the network average content decreases from 530 packets to 450 packets and from 3770 packets to 3710 packets respectively when other parameters remain fixed at $(0.2,2$, $0.3,2,0.5,4)$ for $\left(\mathrm{t}, \mathrm{m}, \mathrm{p}, \alpha, \theta, \beta_{1}\right)$. It is revealed that the utilization characteristics are similar to mean number of packet characteristics. Here also, as the time (t) and the arrival rate of messages $(\alpha)$ increase, the utilization of both the nodes increase for fixed values of the other parameters. As the batch size distribution parameters (m) and (p) increase, the utilization of both the nodes increase when the other parameters are fixed at $(0.2,0.3,0.5,4,8)$ for $\left(\mathrm{t}, \alpha, \theta, \beta_{1}, \beta_{2}\right)$. It is also noticed that as the transmission rate of first transmitter $\left(\beta_{1}\right)$ increases, the utilization of the second node increases while the utilization of the first node decreases when other parameters remain fixed.

From the equations (14 and 15), the throughput and average delay of the network are computed for different values of $t, m, p, \alpha, \theta, \beta_{1}, \beta_{2}$ and are given in Table 3 . The relationship between throughput, average delay and parameters is shown in figure 3 and figure 4 . It is observed that as the time $(\mathrm{t})$ increases from 0.1 seconds to 0.4 seconds, the throughput of the first and second nodes increase from 6240 packets to 16190 packets and from 1250 packets to 7040 packets respectively and there after stabilized when other parameters remain fixed at $(2,0.3$, $2,0.5,4,8)$ for $\left(\mathrm{m}, \mathrm{p}, \alpha, \theta, \beta_{1}, \beta_{2}\right)$. As the batch size distribution parameter $(\mathrm{m})$ varies from 5 to 8 , the throughput of the first and second node increases from 9630 packets to 11560 packets and 2980 packets to 5750 packets respectively when other parameters remain fixed at $(0.2,0.3,2,0.5,4,8)$ for $\left(\mathrm{t}, \mathrm{p}, \alpha, \theta, \beta_{1}, \beta_{2}\right)$.

Table 3: Values of Throughput and mean delay of the communication network with dynamic bandwidth allocation and bulk arrivals

\begin{tabular}{|c|c|c|c|r|r|r|r|r|r|r|}
\hline $\mathbf{t}^{*}$ & $\mathbf{m}$ & $\mathbf{p}$ & $\boldsymbol{\alpha \#}$ & $\mathbf{\theta}$ & $\boldsymbol{\beta}_{\mathbf{1}} \mathbf{\$}$ & $\boldsymbol{\beta}_{\mathbf{2}} \mathbf{\$}$ & $\mathbf{T h p 1}$ & $\mathbf{T h p 2}$ & $\mathbf{W}\left(\mathbf{N}_{\mathbf{1}}\right)$ & $\mathbf{W}_{(\mathbf{N}} \mathbf{)}$ \\
\hline $\mathbf{0 . 1}$ & 2 & 0.3 & 2 & 0.5 & 4 & 8 & 0.624 & 0.125 & 0.311 & 0.128 \\
\hline $\mathbf{0 . 2}$ & 2 & 0.3 & 2 & 0.5 & 4 & 8 & 1.003 & 0.343 & 0.323 & 0.130 \\
\hline $\mathbf{0 . 3}$ & 2 & 0.3 & 2 & 0.5 & 4 & 8 & 1.24 & 0.545 & 0.332 & 0.132 \\
\hline $\mathbf{0 . 4}$ & 2 & 0.3 & 2 & 0.5 & 4 & 8 & 1.391 & 0.704 & 0.338 & 0.133 \\
\hline 0.2 & $\mathbf{5}$ & 0.3 & 2 & 0.5 & 4 & 8 & 0.963 & 0.298 & 0.286 & 0.127 \\
\hline 0.2 & $\mathbf{6}$ & 0.3 & 2 & 0.5 & 4 & 8 & 1.039 & 0.384 & 0.353 & 0.132 \\
\hline 0.2 & $\mathbf{7}$ & 0.3 & 2 & 0.5 & 4 & 8 & 1.103 & 0.478 & 0.428 & 0.136 \\
\hline 0.2 & $\mathbf{8}$ & 0.3 & 2 & 0.5 & 4 & 8 & 1.156 & 0.575 & 0.508 & 0.141 \\
\hline 0.2 & 2 & $\mathbf{0 . 1}$ & 2 & 0.5 & 4 & 8 & 0.975 & 0.311 & 0.297 & 0.128 \\
\hline 0.2 & 2 & $\mathbf{0 . 2}$ & 2 & 0.5 & 4 & 8 & 0.988 & 0.326 & 0.310 & 0.129 \\
\hline 0.2 & 2 & $\mathbf{0 . 3}$ & 2 & 0.5 & 4 & 8 & 1.003 & 0.343 & 0.323 & 0.130 \\
\hline 0.2 & 2 & $\mathbf{0 . 4}$ & 2 & 0.5 & 4 & 8 & 1.02 & 0.362 & 0.338 & 0.131 \\
\hline 0.2 & 2 & 0.3 & $\mathbf{1}$ & 0.5 & 4 & 8 & 0.538 & 0.174 & 0.301 & 0.128 \\
\hline 0.2 & 2 & 0.3 & $\mathbf{2}$ & 0.5 & 4 & 8 & 1.003 & 0.343 & 0.323 & 0.130 \\
\hline 0.2 & 2 & 0.3 & $\mathbf{3}$ & 0.5 & 4 & 8 & 1.406 & 0.510 & 0.346 & 0.131 \\
\hline 0.2 & 2 & 0.3 & $\mathbf{4}$ & 0.5 & 4 & 8 & 1.755 & 0.672 & 0.369 & 0.133 \\
\hline 0.2 & 2 & 0.3 & 2 & 0.5 & $\mathbf{1}$ & 8 & 0.308 & 0.108 & 1.384 & 0.127 \\
\hline 0.2 & 2 & 0.3 & 2 & 0.5 & $\mathbf{2}$ & 8 & 0.575 & 0.200 & 0.674 & 0.128 \\
\hline 0.2 & 2 & 0.3 & 2 & 0.5 & $\mathbf{3}$ & 8 & 0.806 & 0.277 & 0.439 & 0.129 \\
\hline 0.2 & 2 & 0.3 & 2 & 0.5 & $\mathbf{4}$ & 8 & 1.003 & 0.343 & 0.323 & 0.130 \\
\hline 0.2 & 2 & 0.3 & 2 & 0.5 & 4 & $\mathbf{1}$ & 1.003 & 0.253 & 0.323 & 0.209 \\
\hline 0.2 & 2 & 0.3 & 2 & 0.5 & 4 & $\mathbf{2}$ & 1.003 & 0.287 & 0.323 & 0.1747 \\
\hline 0.2 & 2 & 0.3 & 2 & 0.5 & 4 & $\mathbf{3}$ & 1.003 & 0.317 & 0.323 & 0.149 \\
\hline 0.2 & 2 & 0.3 & 2 & 0.5 & 4 & $\mathbf{5}$ & 1.003 & 03436 & 0.323 & 0.130 \\
\hline 0.2 & 2 & 0.3 & 2 & $\mathbf{0 . 1}$ & 4 & 8 & 1.003 & 0.071 & 0.323 & 0.126 \\
\hline 0.2 & 2 & 0.3 & 2 & $\mathbf{0 . 2}$ & 4 & 8 & 1.003 & 0.141 & 0.323 & 0.127 \\
\hline & $*$ & 5 & & & & \\
\hline
\end{tabular}

$*=$ Seconds, \#=Multiples of 10, 000 messages/seconds, $\$=$ Multiples of 10,000 packets/second 


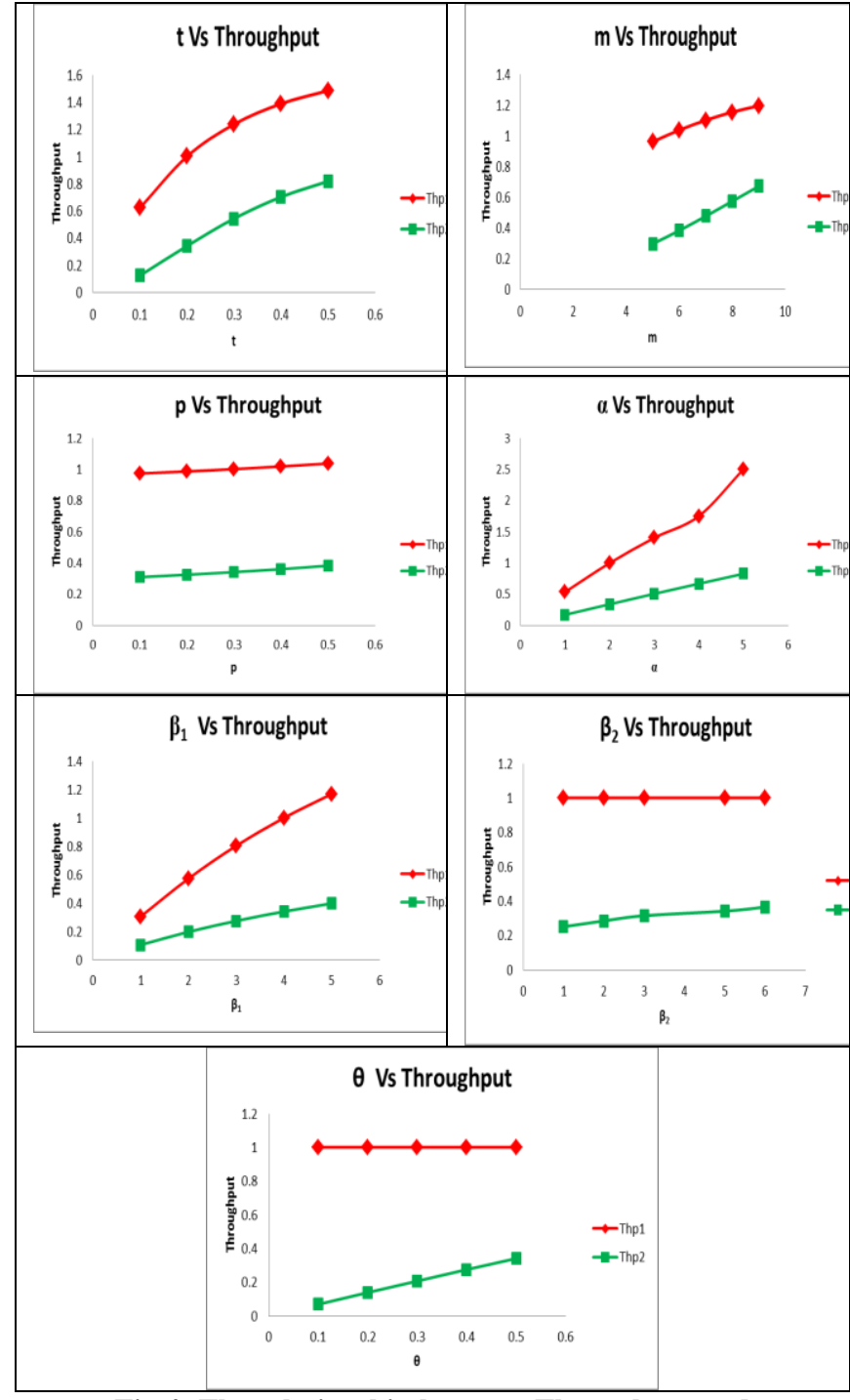

Fig 4: The relationship between Throughput and various parameters

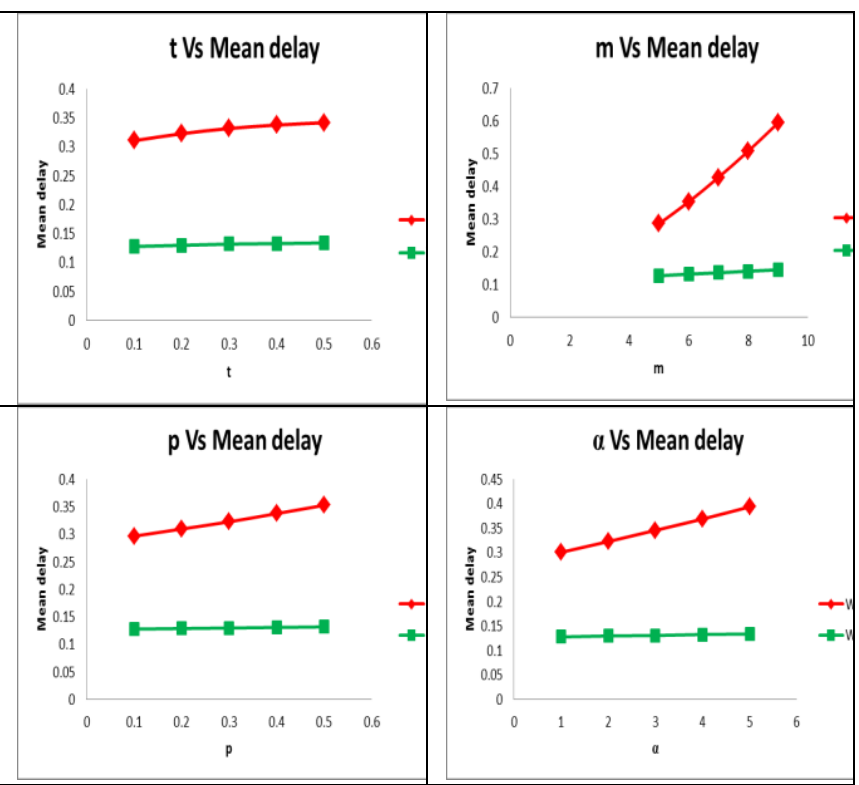

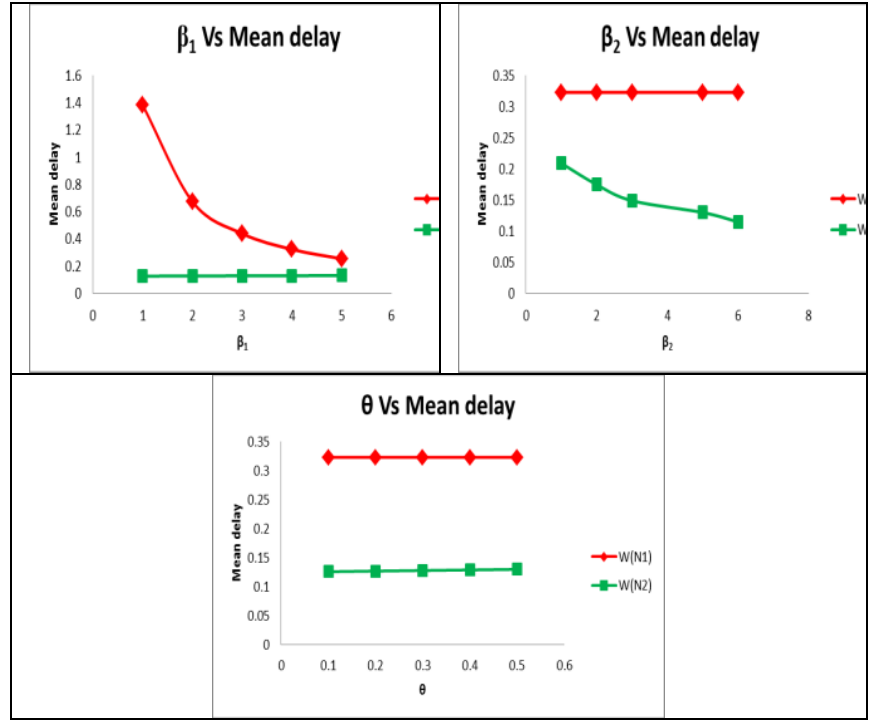

Fig 5: The relationship between Mean Delay and various parameters

As the batch size distribution parameter (p) varies from 0.1 to 0.4 , the throughput of the first and second nodes increase from 9750 packets to 10200 packets and 3110 packets to 3620 packets respectively when other parameters remain fixed at $(0.2,2,2,0.5,4,8)$ for $(\mathrm{t}, \mathrm{m}, \alpha$, $\left.\theta, \beta_{1}, \beta_{2}\right)$. As the arrival rate $(\alpha)$ varies from $1 \times 10^{4}$ messages $/ \mathrm{sec}$ to $4 \times 10^{4}$ messages $/ \mathrm{sec}$, it is observed that the throughput of the first and second nodes increase 5380 packets to 17550 packets and from 1740 packets to 6720 packets respectively, when other parameters remain fixed at $(0.2,2,0.3,0.5,4,8)$ for $\left(\mathrm{t}, \mathrm{m}, \mathrm{p}, \theta, \beta_{1}, \beta_{2}\right)$. As the arrival rate $(\alpha)$ varies from $1 \times 10^{4}$ messages $/ \mathrm{sec}$ to $4 \times 10^{4}$ messages/sec, it is observed that the throughput of the first and second nodes increases from 5380 packets to 17550 packets and from 1740 packets to 6720 packets respectively, when other parameters remain fixed at $(0.2$, $2,0.3,0.5,4,8)$ for $\left(\mathrm{t}, \mathrm{m}, \mathrm{p}, \theta, \beta_{1}, \beta_{2}\right)$. When the probability of packets forwarded $(\theta)$ varies from $0.1 \times 10^{4}$ packet/sec to $0.4 \times 10^{4}$ packet/sec, the throughput of the first remain unchanged as 10030 packets and second node increases from 710 packets to 2770packets respectively, when other parameters remain fixed at $(0.2,2,0.3,2,4,8)$ for $\left(\mathrm{t}, \mathrm{m}, \mathrm{p}, \alpha, \beta_{1}, \beta_{2}\right)$. As the transmission rate of first transmitter $\left(\beta_{1}\right)$ varies from $1 \times 10^{4}$ packets/sec to $4 \times 10^{4}$ packets/sec, the throughput of the first and second nodes increase from 3080 packets 10030 packets and from 1080 packets to 3430 packets respectively, when other parameters remain fixed at $(0.2,2,0.3,2,0.5,8)$ for $(\mathrm{t}, \mathrm{m}$, $\left.\mathrm{p}, \alpha, \theta, \beta_{2}\right)$. As the transmission rate of second node $\left(\beta_{2}\right)$ varies from $1 \times 10^{4}$ packets $/ \mathrm{sec}$ to $4 \times 10^{4}$ packets $/ \mathrm{sec}$, the throughput of second node increases from 2530 packets to 3430 packets, when other parameters remain fixed at $(0.2$, $2,0.3,2,0.5,4)$ for $\left(\mathrm{t}, \mathrm{m}, \mathrm{p}, \alpha, \theta, \beta_{1}\right)$.

From table 4 , it is also observed that as time $(\mathrm{t})$ varies from 0.1 to 0.4 seconds, the mean delay of the first and second buffers increase from $31.100 \mu$ s to $33.800 \mu \mathrm{s}$ and from $12.800 \mu \mathrm{s}$ to $13.300 \mu \mathrm{s}$ respectively, when other parameters remain fixed $(2,0.3,2,0.5,4,8)$ for $(\mathrm{m}, \mathrm{p}, \alpha$, $\left.\theta, \beta_{1}, \beta_{2}\right)$. As the batch size distribution parameter (m) varies from $5 \times 10^{4}$ packets $/ \mathrm{sec}$ to $8 \times 10^{4}$ packets $/ \mathrm{sec}$, the mean delay of the first and second buffers increase from $28.600 \mu \mathrm{s}$ to $50.800 \mu \mathrm{s}$ and $12.700 \mu \mathrm{s}$ to $14.100 \mu \mathrm{s}$ respectively when other parameters remain fixed at $(0.2$, $0.3,2,0.54,8)$ for $\left(\mathrm{t}, \mathrm{p}, \alpha, \theta, \beta_{1}, \beta_{2}\right)$. As the batch size 
distribution parameter (p) varies from $0.1 \times 10^{4}$ packets $/ \mathrm{sec}$ to $0.4 \times 10^{4}$ packets/sec, the mean delay of the first and second buffers increase from $29.700 \mu$ s to $33.800 \mu$ s and $12.800 \mu \mathrm{s}$ to $13.200 \mu \mathrm{s}$ respectively when other parameters remain fixed at $(0.2,2,2,0.5,4,8)$ for $(\mathrm{t}, \mathrm{m}, \alpha$, $\left.\theta, \beta_{1}, \beta_{2}\right)$. When the arrival rate $(\alpha)$ varies from $1 \times 10^{4}$ messages $/ \mathrm{sec}$ to $4 \times 10^{4}$ messages $/ \mathrm{sec}$, the mean delay of the first and second buffers increase from $30.100 \mu$ s to $36.900 \mu \mathrm{s}$ and $12.800 \mu \mathrm{s}$ to $13.100 \mu \mathrm{s}$ respectively, when other parameters remain fixed at $(0.2,2,0.3,0.5,4,8)$ for $\left(\mathrm{t}, \mathrm{m}, \mathrm{p}, \theta, \beta_{1}, \beta_{2}\right)$. As the probability of packets forwarded $(\theta)$ varies from $0.1 \times 10^{4} \mathrm{packet} / \mathrm{sec}$ to $0.4 \times 10^{4} \mathrm{packet} / \mathrm{sec}$, the mean delay of the first buffer remain unchanged as $32.300 \mu \mathrm{s}$ and the mean delay of the second buffer increases from $12.600 \mu \mathrm{s}$ to $12.900 \mu \mathrm{s}$ when other parameters remain fixed at $(0.2,2,0.3,2,4,8)$ for $(\mathrm{t}, \mathrm{m}, \mathrm{p}$, $\left.\alpha, \beta_{1}, \beta_{2}\right)$.

As the transmission rate of first transmitter $\left(\beta_{1}\right)$ varies from $1 \times 10^{4}$ packets $/ \mathrm{sec}$ to $5 \times 10^{4}$ packets $/ \mathrm{sec}$, the mean delay of the first buffer decreases from $138.40 \mu$ s to $32.300 \mu \mathrm{s}$ and the mean delay of the second buffer increases from $12.700 \mu \mathrm{s}$ to $13.000 \mu \mathrm{s}$, when other parameters remain fixed at $(0.2,2,0.3,2,0.5,8)$ for $(\mathrm{t}, \mathrm{m}$, $\left.\mathrm{p}, \alpha, \theta, \beta_{2}\right)$. As the transmission rate of second transmitter $\left(\beta_{2}\right)$ varies from $1 \times 10^{4}$ packets/sec to $4 \times 10^{4}$ packets $/ \mathrm{sec}$, the mean delay of the second buffer decreases from $20.900 \mu \mathrm{s}$ to $13.000 \mu \mathrm{s}$, when other parameters remain fixed at $(0.2,2,0.3,2,0.5,4)$ for $\left(\mathrm{t}, \mathrm{m}, \mathrm{p}, \alpha, \theta, \beta_{1}\right)$. The variance of the number of packets in each buffer, the coefficient of variation of the number of packets in first and second buffers are computed and given in Table 4 .

Table 4: Values of Variance and Coefficient of Variation of the number of packets the communication network with dynamic bandwidth allocation and bulk arrivals

\begin{tabular}{|c|c|c|c|c|c|c|c|c|c|c|}
\hline t* & $\mathbf{m}$ & p & $\alpha \#$ & $\theta$ & $\beta_{1} \$$ & $\beta_{2} \$$ & $\operatorname{Var}\left(\mathrm{N}_{1}\right)$ & $\operatorname{Var}\left(\mathbf{N}_{2}\right)$ & $\mathrm{CV}\left(\mathrm{N}_{1}\right)$ & $\mathrm{CV}\left(\mathrm{N}_{2}\right)$ \\
\hline 0.1 & 2 & 0.3 & 2 & 0.5 & 4 & 8 & 0.243 & 0.016 & 2.539 & 8.595 \\
\hline 0.2 & 2 & 0.3 & 2 & 0.5 & 4 & 8 & 0.394 & 0.046 & 1.939 & 4.811 \\
\hline 0.3 & 2 & 0.3 & 2 & 0.5 & 4 & 8 & 0.491 & 0.074 & 1.705 & 3.793 \\
\hline 0.4 & 2 & 0.3 & 2 & 0.5 & 4 & 8 & 0.554 & 0.097 & 1.586 & 3.319 \\
\hline 0.2 & 5 & 0.3 & 2 & 0.5 & 4 & 8 & 0.275 & 0.038 & 1.906 & 5.136 \\
\hline 0.2 & 6 & 0.3 & 2 & 0.5 & 4 & 8 & 0.500 & 0.053 & 1.926 & 4.566 \\
\hline 0.2 & 7 & 0.3 & 2 & 0.5 & 4 & 8 & 0.814 & 0.072 & 1.912 & 4.129 \\
\hline 0.2 & 8 & 0.3 & 2 & 0.5 & 4 & 8 & 1.226 & 0.094 & 1.885 & 3.79 \\
\hline 0.2 & 2 & 0.1 & 2 & 0.5 & 4 & 8 & 0.311 & 0.04 & 1.924 & 5.033 \\
\hline 0.2 & 2 & 0.2 & 2 & 0.5 & 4 & 8 & 0.350 & 0.043 & 1.935 & 4.925 \\
\hline 0.2 & 2 & 0.3 & 2 & 0.5 & 4 & 8 & 0.394 & 0.046 & 1.939 & 4.811 \\
\hline 0.2 & 2 & 0.4 & 2 & 0.5 & 4 & 8 & 0.444 & 0.049 & 1.941 & 4.692 \\
\hline 0.2 & 2 & 0.3 & 1 & 0.5 & 4 & 8 & 0.197 & 0.023 & 2.742 & 6.804 \\
\hline 0.2 & 2 & 0.3 & 2 & 0.5 & 4 & 8 & 0.394 & 0.046 & 1.939 & 4.811 \\
\hline 0.2 & 2 & 0.3 & 3 & 0.5 & 4 & 8 & 0.592 & 0.069 & 1.583 & 3.928 \\
\hline 0.2 & 2 & 0.3 & 4 & 0.5 & 4 & 8 & 0.789 & 0.092 & 1.371 & 3.402 \\
\hline 0.2 & 2 & 0.3 & 2 & 0.5 & 1 & 8 & 0.543 & 0.014 & 1.727 & 4.455 \\
\hline 0.2 & 2 & 0.3 & 2 & 0.5 & 2 & 8 & 0.485 & 0.026 & 1.796 & 4.811 \\
\hline 0.2 & 2 & 0.3 & 2 & 0.5 & 3 & 8 & 0.436 & 0.037 & 1.866 & 5.358 \\
\hline 0.2 & 2 & 0.3 & 2 & 0.5 & 4 & 8 & 0.394 & 0.046 & 1.939 & 6.319 \\
\hline 0.2 & 2 & 0.3 & 2 & 0.5 & 4 & 1 & 0.359 & 0.055 & 1.939 & 4.432 \\
\hline 0.2 & 2 & 0.3 & 2 & 0.5 & 4 & 2 & 0.359 & 0.052 & 1.939 & 4.559 \\
\hline 0.2 & 2 & 0.3 & 2 & 0.5 & 4 & 3 & 0.359 & 0.049 & 1.939 & 4.686 \\
\hline 0.2 & 2 & 0.3 & 2 & 0.5 & 4 & 5 & 0.359 & 0.046 & 1.939 & 4.811 \\
\hline 0.2 & 2 & 0.3 & 2 & 0.1 & 4 & 8 & 0.359 & 0.009 & 1.939 & 10.62 \\
\hline 0.2 & 2 & 0.3 & 2 & 0.2 & 4 & 8 & 0.359 & 0.018 & 1.939 & 7.536 \\
\hline 0.2 & 2 & 0.3 & 2 & 0.3 & 4 & 8 & 0.359 & 0.027 & 1.939 & 6.172 \\
\hline 0.2 & 2 & 0.3 & 2 & 0.4 & 4 & 8 & 0.359 & 0.037 & 1.939 & 5.362 \\
\hline
\end{tabular}

$\$=$ Multiples of 10,000 packets/second

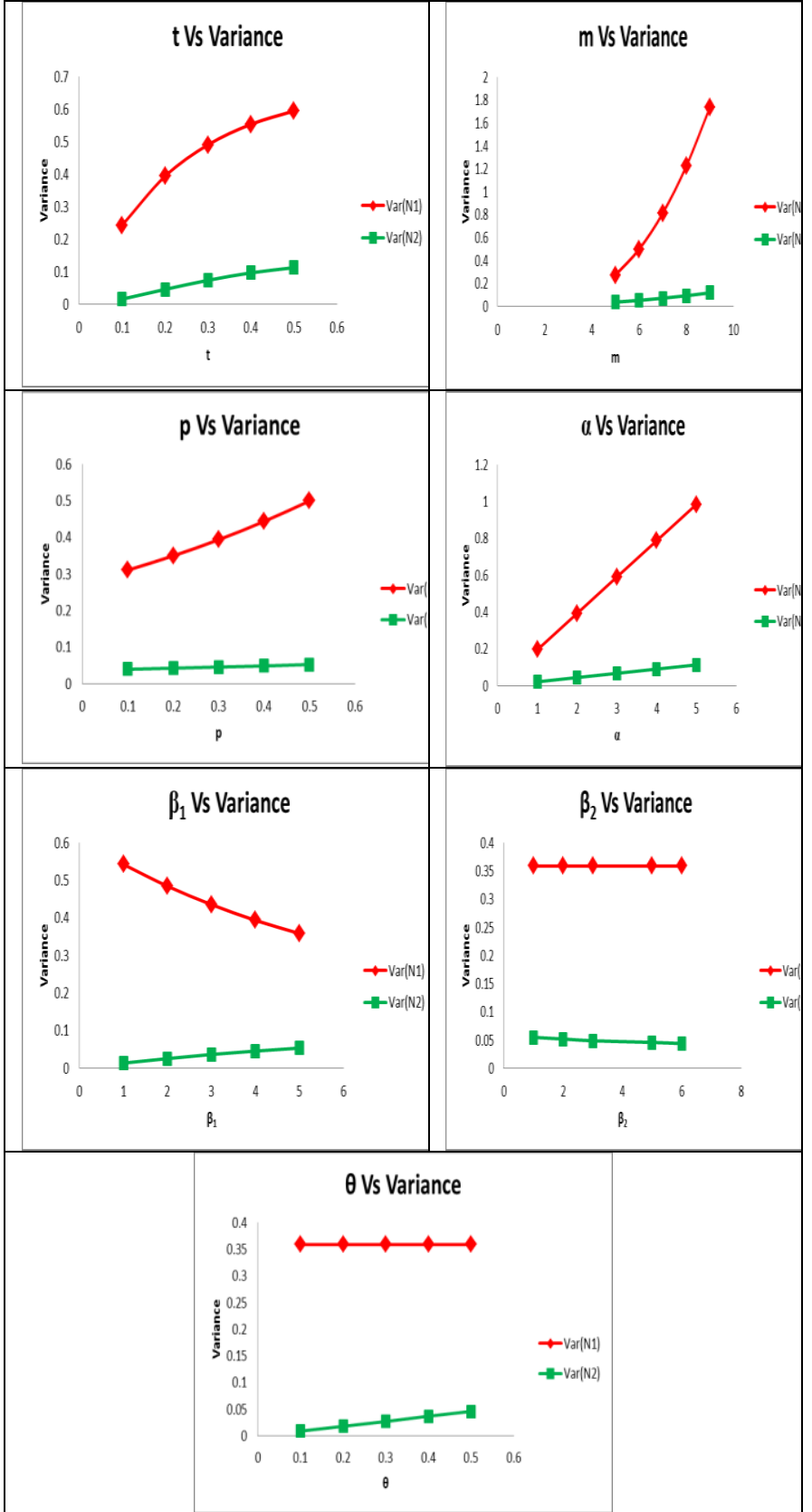

Fig 6: The relationship between Variance and various parameters

If the variance increases then the burstness of the buffers will be high. Hence, the parameters are to be adjusted such that the variance of the buffer content in each buffer must be small. The coefficient of variation of the number of packets in each buffer helps us to understand the consistency of the traffic flow through buffers. If coefficient of variation is large then the flow is inconsistent. It also helps us to compare the smooth flow of packets in two or more nodes. It is observed that, as the time $(\mathrm{t})$ and the batch size distribution parameter $(\mathrm{m})$ increase, the variance of first and second buffers increased and the coefficient of variation of the number of packet in the first and second buffers decreased. As the batch size distribution parameter $(p)$ increases, the variance of first and second buffers are increasing and the coefficient of variation of the number of packets in the first buffer is increasing and for the second buffer is decreasing. From this analysis it is observed that the dynamic bandwidth 
allocation strategy has a significant influence on all performance measures of the network. It is further observed that the performance measures are highly sensitive towards smaller values of time. Hence, it is optimal to consider bulk arrivals with dynamic bandwidth allocation and evaluate the performance under transient condition. It is also observed that the congestion in buffers and delays in transmission can be reduced to a minimum level by adopting dynamic bandwidth allocation. This phenomenon has a vital bearing on quality of transmission (service).

\section{OPTIMAL POLICIES OF THE MODEL}

In this section, we derive the optimal operating policies of the communication networks under study. Here, it is assumed that the service provider of the communication network is interested in maximization of the profit function at a given time t. Let the service provider gets an amount of $R_{i}$ units per every unit of time of the system busy at $\mathrm{i}^{\text {th }}$ transmitter $(\mathrm{i}=1,2)$. In other words, he gets revenue of $R_{i}$ units per every unit of throughput of the $i^{\text {th }}$ transmitter. Therefore, the total revenue of the communication network at time $t$ is,

$\mathrm{R}$ ( $\mathrm{t})=\mathrm{R}_{1}$. (Throughput of first transmitter) $+\mathrm{R}_{2}$. (Throughput of second transmitter) (34)

$$
\begin{aligned}
& \mathrm{R}(\mathrm{t})=\mathrm{R}_{1} \cdot \beta_{1}(1-\exp )\left[\alpha \sum_{\mathrm{k}=1}^{\mathrm{m}} \sum_{\mathrm{r}=1}^{\mathrm{k}} \frac{\left.{ }^{\mathrm{m}} \mathrm{C}_{\mathrm{k}} \mathrm{p}^{\mathrm{k}}(1-\mathrm{p})^{\mathrm{m}-\mathrm{k}}{ }^{\mathrm{k}} \mathrm{C}_{\mathrm{r}}(-1)^{3 \mathrm{r}} \frac{\left(1-\mathrm{e}^{-\mathrm{r} \beta_{1} \mathrm{t}}\right)}{\mathrm{r} \beta_{1}}\right]}{+\mathrm{R}_{2} \cdot \beta_{2}(1-\exp )\left[\alpha \sum_{\mathrm{k}=1}^{\mathrm{m}} \sum_{\mathrm{r}=1}^{\mathrm{k}} \sum_{\mathrm{J}=0}^{\mathrm{r}}(-1)^{3 \mathrm{r}-\mathrm{J}} \frac{{ }^{\mathrm{m}} \mathrm{C}_{\mathrm{k}} \mathrm{p}^{\mathrm{k}}(1-\mathrm{p})^{\mathrm{m}-\mathrm{k}}}{1-(1-\mathrm{p})^{\mathrm{m}}}\right.}\right. \\
& \left.\left({ }^{\mathrm{k}} \mathrm{C}_{\mathrm{r}}\right)\left({ }^{\mathrm{r}} \mathrm{C}_{\mathrm{J}}\right)\left(\frac{\theta \beta_{1}}{\beta_{2}-\beta_{1}}\right)^{\mathrm{r}} \frac{\left(1-\mathrm{e}^{-\left[\mathrm{J} \beta_{2}+(\mathrm{r}-\mathrm{J}) \beta_{1}\right] \mathrm{t}}\right)}{\mathrm{J} \beta_{2}+(\mathrm{r}-\mathrm{J}) \beta_{1}}\right]
\end{aligned}
$$

Let $\mathrm{A}$ is the set up cost for operating the communication network. $\mathrm{C}_{1}$ is the penalty cost due to waiting of a customer in the first transmitter. $\mathrm{C}_{2}$ is the penalty cost due to waiting of a customer in the second transmitter. Therefore, the total cost for operating the communication network at time $\mathrm{t}$ is,

$\mathrm{C}(\mathrm{t})=\mathrm{A}+\mathrm{C}_{1} *$ (Average waiting time of a customer in first transmitter) $+\mathrm{C}_{2} *$ (Average waiting time of a customer in second transmitter) (36)

To obtain the optimal values of $\beta_{1}$ and $\beta_{2}$, maximizing $P$ $(\mathrm{t})$, with respect to $\beta_{1}$ and $\beta_{2}$ and verify the hessian matrix $\frac{\partial \mathrm{P}(\mathrm{t})}{\partial \beta_{1}}=0$ implies

$$
\begin{aligned}
& C(t)=A+C_{1} \cdot \frac{\frac{\alpha}{\beta_{1}}\left[\sum_{k=1}^{m} \frac{{ }^{m} C_{k} p^{k}(1-p)^{m-k}}{1-(1-p)^{m}} \cdot k\left(1-e^{-\beta_{1} t}\right)\right]}{\beta_{1}(1-\exp )\left[\alpha \sum_{k=1}^{m} \sum_{r=1}^{k} \frac{{ }^{m} C_{k} p^{k}(1-p)^{m-k}}{1-(1-p)^{m}} C_{r}(-1)^{3 r} \frac{\left(1-e^{-r \beta_{1} t}\right)}{r \beta_{1}}\right]}
\end{aligned}
$$

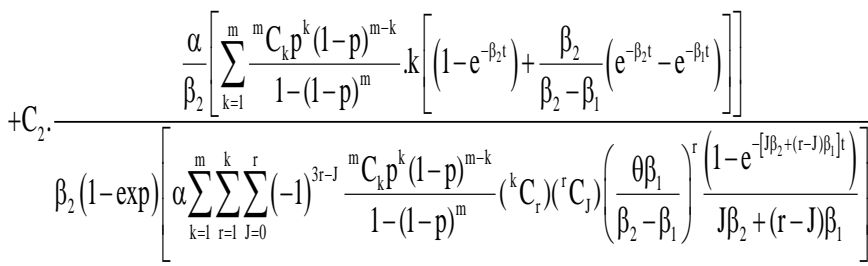

Substituting the values of $\mathrm{R}(\mathrm{t})$ and $\mathrm{C}(\mathrm{t})$ from equation (35) and (37) respectively we get total cost function as,

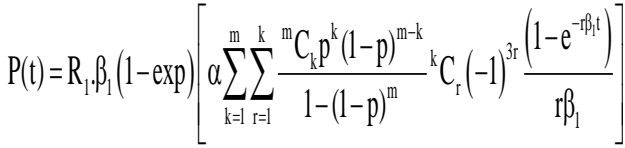

$$
\begin{aligned}
& +R_{2} \cdot \beta_{2}(1-\exp )\left[\alpha \sum_{\mathrm{k}=1}^{\mathrm{m}} \sum_{\mathrm{r}=1}^{\mathrm{k}} \sum_{\mathrm{J}=0}^{\mathrm{r}}(-1)^{3 \mathrm{r}-\mathrm{J}} \frac{{ }^{\mathrm{m}} \mathrm{C}_{\mathrm{k}} \mathrm{p}^{\mathrm{k}}(1-\mathrm{p})^{\mathrm{m}-\mathrm{k}}}{1-(1-\mathrm{p})^{\mathrm{m}}}\left({ }^{\mathrm{k}} \mathrm{C}_{\mathrm{r}}\right)\left({ }^{\mathrm{r}} \mathrm{C}_{\mathrm{J}}\right)\left(\frac{\theta \beta_{1}}{\beta_{2}-\beta_{1}}\right)^{\mathrm{r}}\left(\frac{\left(1-\mathrm{e}^{-\left[\mathrm{J} \beta_{2}+(\mathrm{r}-\mathrm{J}) \beta_{1}\right] \mathrm{t}}\right)}{\mathrm{J} \beta_{2}+(\mathrm{r}-\mathrm{J}) \beta_{1}}\right]\right.
\end{aligned}
$$

$$
-C_{1} \cdot \frac{\frac{\alpha}{\beta_{1}}\left[\sum_{k=1}^{m} \frac{{ }^{m} C_{k} p^{k}(1-p)^{m-k}}{1-(1-p)^{m}} \cdot k\left(1-e^{-\beta_{1} t}\right)\right]}{\beta_{1}(1-\exp )\left[\alpha \sum_{k=1}^{m} \sum_{r=1}^{k} \frac{{ }^{m} C_{k} p^{k}(1-p)^{m-k}}{1-(1-p)^{m}}{ }^{k} C_{r}(-1)^{3 r} \frac{\left(1-e^{-r p_{t} t}\right)}{r \beta_{1}}\right]}
$$

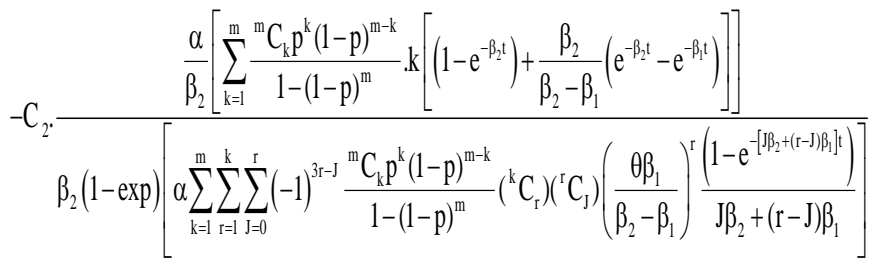

$$
\begin{aligned}
& \frac{\partial \mathrm{P}(\mathrm{t})}{\partial \beta_{1}}=\mathrm{R}_{1} \cdot \beta_{1}(1-\exp )\left[\alpha \sum_{\mathrm{k}=1}^{\mathrm{m}} \sum_{\mathrm{r}=1}^{\mathrm{k}} \frac{{ }^{\mathrm{m}} \mathrm{C}_{\mathrm{k}} \mathrm{p}^{\mathrm{k}}(1-\mathrm{p})^{\mathrm{m}-\mathrm{k}}}{1-(1-\mathrm{p})^{\mathrm{m}}}{ }^{\mathrm{k}} \mathrm{C}_{\mathrm{r}}(-1)^{3 \mathrm{r}} \frac{\left(1-\mathrm{e}^{-\mathrm{r} \beta_{1} \mathrm{t}}\right)}{\mathrm{r} \beta_{1}}\right] \\
& +R_{2}, \beta_{2}(1-\exp )\left[\alpha \sum_{\mathrm{k}=1}^{\mathrm{m}} \sum_{\mathrm{r}=1}^{\mathrm{k}} \sum_{\mathrm{J}=0}^{\mathrm{r}}(-1)^{3 \mathrm{r}-\mathrm{J}} \frac{{ }^{\mathrm{m}} \mathrm{C}_{\mathrm{k}} \mathrm{p}^{\mathrm{k}}(1-\mathrm{p})^{\mathrm{m}-\mathrm{k}}}{1-(1-\mathrm{p})^{\mathrm{m}}}\left({ }^{\mathrm{k}} \mathrm{C}_{\mathrm{r}}\right)\left({ }^{\mathrm{r}} \mathrm{C}_{\mathrm{J}}\right)\left(\frac{\theta \beta_{1}}{\beta_{2}-\beta_{1}}\right)^{\mathrm{r}} \frac{\left(1-\mathrm{e}^{-\left[\mathrm{J} \beta_{2}+(\mathrm{r}-\mathrm{J}) \beta_{1} \mathrm{t}\right]}\right)}{\mathrm{J} \beta_{2}+(\mathrm{r}-\mathrm{J}) \beta_{1}}\right]
\end{aligned}
$$

$$
-\mathrm{C}_{1} \cdot \frac{\frac{\alpha}{\beta_{1}}\left[\sum_{\mathrm{k}=1}^{\mathrm{m}} \frac{{ }^{\mathrm{m}} \mathrm{C}_{\mathrm{k}} \mathrm{p}^{\mathrm{k}}(1-\mathrm{p})^{\mathrm{m}-\mathrm{k}}}{1-(1-\mathrm{p})^{\mathrm{m}}} \cdot \mathrm{k}\left(1-\mathrm{e}^{-\beta_{1} \mathrm{t}}\right)\right]}{\beta_{1}(1-\exp )\left[\alpha \sum_{\mathrm{k}=1}^{\mathrm{m}} \sum_{\mathrm{r}=1}^{\mathrm{k}} \frac{{ }^{\mathrm{m}} \mathrm{C}_{\mathrm{k}} \mathrm{p}^{\mathrm{k}}(1-\mathrm{p})^{\mathrm{m}-\mathrm{k}}}{1-(1-\mathrm{p})^{\mathrm{m}}}{ }^{\mathrm{k}} \mathrm{C}_{\mathrm{r}}(-1)^{3 \mathrm{r}} \frac{\left(1-\mathrm{e}^{-\mathrm{r} \beta_{1} \mathrm{t}}\right)}{\mathrm{r} \beta_{1}}\right]}
$$




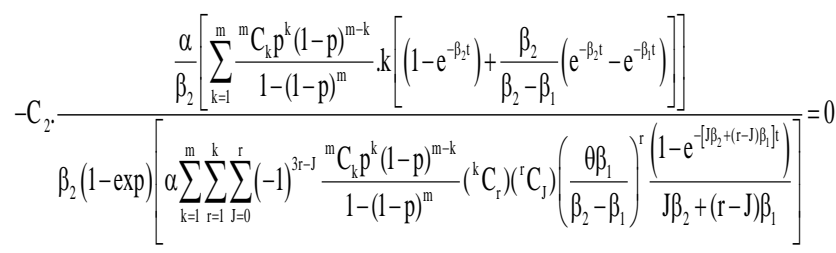

$$
\begin{aligned}
& \frac{\partial \mathrm{P}(\mathrm{t})}{\partial \beta_{2}}=0 \text { Implies }
\end{aligned}
$$

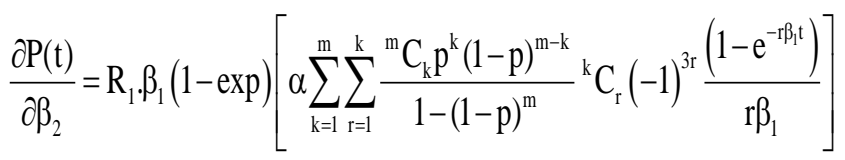

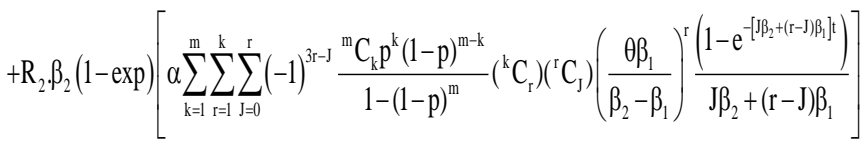$$
-C_{1} \cdot \frac{\frac{\alpha}{\beta_{1}}\left[\sum_{k=1}^{m} \frac{{ }^{m} C_{k} p^{k}(1-p)^{m-k}}{1-(1-p)^{m}} k\left(1-e^{-\beta_{1} t}\right)\right]}{\beta_{1}(1-\exp )\left[\alpha \sum_{k=1}^{m} \sum_{r=1}^{k} \frac{{ }^{m} C_{k} p^{k}(1-p)^{m-k}}{1-(1-p)^{m}}{ }^{k} C_{r}(-1)^{3 r} \frac{\left(1-e^{-r \beta_{1} t}\right)}{r \beta_{1}}\right]}
$$

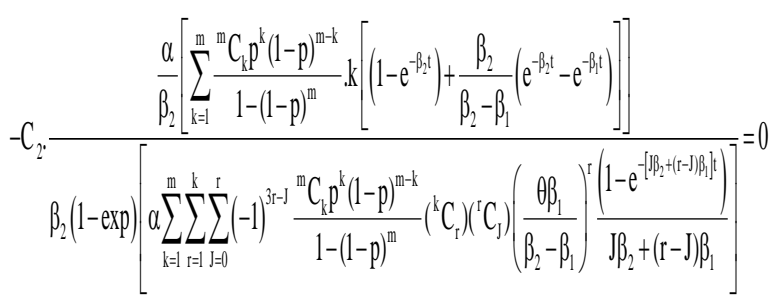

The determinant of the Hessian matrix is,

$$
|D|=\left|\begin{array}{ll}
\frac{\partial^{2} \mathrm{P}(\mathrm{t})}{\partial \beta_{1}^{2}} & \frac{\partial^{2} \mathrm{P}(\mathrm{t})}{\partial \beta_{1} \partial \beta_{2}} \\
\frac{\partial^{2} \mathrm{P}(\mathrm{t})}{\partial \beta_{1} \partial \beta_{2}} & \frac{\partial^{2} \mathrm{P}(\mathrm{t})}{\partial \beta_{2}{ }^{2}}
\end{array}\right|<0
$$

Solving the equations (39) and (40) with respect to $\beta_{1}$ and $\beta_{2}$ and verifying the condition (41), for the given parameters of $\alpha, \mathrm{m}, \mathrm{p}$ and $\mathrm{t}$ we get the optimal values of transmission rates at transmitter 1 and transmitter 2 as $\beta_{1}{ }^{*}$ and $\beta_{2}{ }^{*}$ respectively.

Substituting the values of $\beta_{1}{ }^{*}$ and $\beta_{2}{ }^{*}$ in equation (40), we get the optimal value of the profit at given time $t$ as

$\mathrm{P}^{*}(\mathrm{t})=\mathrm{R}_{1} \cdot \beta_{1}^{*}(1-\exp )\left[\alpha \sum_{\mathrm{k}=1}^{\mathrm{m}} \sum_{\mathrm{r}=1}^{\mathrm{k}} \frac{{ }^{\mathrm{m}} \mathrm{C}_{\mathrm{k}} \mathrm{p}^{\mathrm{k}}(1-\mathrm{p})^{\mathrm{m}-\mathrm{k}}}{1-(1-\mathrm{p})^{\mathrm{m}}}{ }^{\mathrm{k}} \mathrm{C}_{\mathrm{r}}(-1)^{3 \mathrm{r}} \frac{\left(1-\mathrm{e}^{-\mathrm{r} \mathrm{p}_{1}{ }^{*} \mathrm{t}}\right)}{\mathrm{r} \beta_{1}{ }^{*}}\right]$

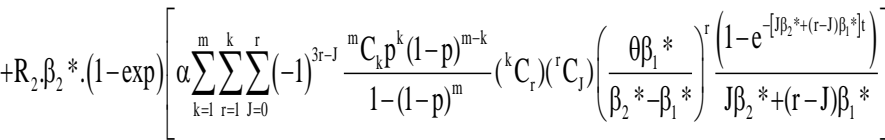

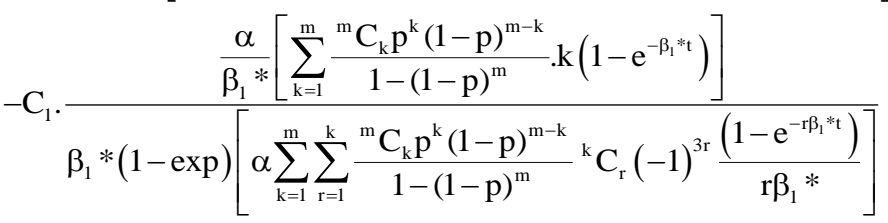

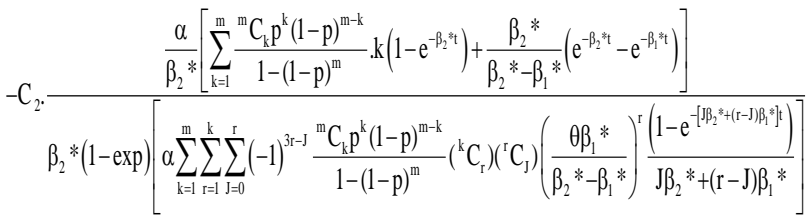

\section{NUMERICAL ILLUSTRATION AND SENSITIVITY ANALYSIS}

In this section, we demonstrate the solution procedure through a numerical illustration. Consider the service provider to a communication network is operating a twotransmitter tandem communication network. Let the estimated cost of revenue per unit throughput of transmitter 1 is $R_{1}$ varies from 0.3 to 0.6 and the revenue per unit of throughput of transmitter $2 \mathrm{R}_{2}$ varies from 0.3 to 0.6. It is estimated the composite arrival rate of messages per unit time is $\alpha$ varies from 1.5 to 1.9 . The batch size distribution parameters of the number of packets that are generated from a message are considered to varies from 1 to 7 for $\mathrm{m}$ and 0.3 to 0.9 for $\mathrm{p}$. Let the penalty cost per a packet waiting time at transmitter 1 for transmission per unit time is $\mathrm{C}_{1}$ varies from 0.07 to 0.10 . The penalty cost per a packet waiting time at transmitter 2 for transmission per unit time is $\mathrm{C}_{2}$ varies from 0.07 to 0.10 . With these costs and parameters, the optimal values of transmission rates $\beta_{1}$ and $\beta_{2}$ are obtained using Newton Ramp sons Method and Mathcad. The optimal value of transmission rate of first transmitter and transmission rate of second transmitter, optimal profit parameters are computed and shown in Table 6 . It is observed that the transmission rate of first transmitter $\left(\beta_{1}\right)$ and the transmission rate of second transmitter $\left(\beta_{2}\right)$ are highly sensitive with respect to changes in time. As time (t) varies from 0.1 to 0.4 second, the transmission rate of first transmitter $\left(\beta_{1}\right)$ reduces from 2.667 to 2.657 , the transmission rate of second transmitter $\left(\beta_{2}\right)$ reduce from 3.477 to 3.462 respectively and the total optimal cost function decreases from 1.841 to 1.827 when other parameters are fixed at $(4,0.1,2,0.18,0.5,0.5,0.1,0.1)$ for $\left(\mathrm{m}, \mathrm{p}, \alpha, \theta, \mathrm{R}_{1}, \mathrm{R}_{2}, \mathrm{C}_{1}, \mathrm{C}_{2}\right)$. When the batch size distribution of number of packets a message can be converted $(\mathrm{m})$ varies from $1 \times 10^{4}$ packets $/ \mathrm{sec}$ to $5 \times 10^{4}$ packets/sec, the transmission rate of first transmitter $\left(\beta_{1}\right)$ increases from 1.653 to 1.711 and the transmission rate of second transmitter $\left(\beta_{2}\right)$ increases from 3.660 to 4.526 and the total optimal cost function increases from 1.881 to 2.717 when other parameters are fixed at $(0.5,0.1,2,0.18$, $0.5,0.5,0.1,0.1)$ for (t, $\left.p, \alpha, \theta, R_{1}, R_{2}, C_{1}, C_{2}\right)$. 
Table 6: The optimal Values of $\beta_{1}$ * and $\beta_{2}$ *

\begin{tabular}{|l|l|l|l|l|l|l|l|l|l|l|l|l|}
\hline $\mathbf{t}$ & $\mathbf{m}$ & $\mathbf{p}$ & $\boldsymbol{\alpha}$ & $\boldsymbol{\theta}$ & $\mathbf{R}_{\mathbf{1}}$ & $\mathbf{R}_{\mathbf{2}}$ & $\mathbf{C}_{\mathbf{1}}$ & $\mathbf{C}_{\mathbf{2}}$ & $\boldsymbol{\beta}_{\mathbf{1}}{ }^{*}$ & $\boldsymbol{\beta}_{\mathbf{2}}{ }^{*}$ & $\mathbf{R}$ & $\mathbf{D}_{\mathbf{1}}{ }^{{ }^{*}}$ \\
\hline $\mathbf{0 . 1}$ & 4 & 0.1 & 2 & 0.18 & 0.5 & 0.5 & 0.1 & 0.1 & 2.667 & 3.477 & 1.841 & -0.924 \\
\hline $\mathbf{0 . 2}$ & 4 & 0.1 & 2 & 0.18 & 0.5 & 0.5 & 0.1 & 0.1 & 2.662 & 3.476 & 1.832 & -0.912 \\
\hline 0.5 & $\mathbf{1}$ & 0.1 & 2 & 0.18 & 0.5 & 0.5 & 0.1 & 0.1 & 1.653 & 1.881 & 0.956 & -0.756 \\
\hline 0.5 & $\mathbf{3}$ & 0.1 & 2 & 0.18 & 0.5 & 0.5 & 0.1 & 0.1 & 1.656 & 2.461 & 0.966 & -0.742 \\
\hline 0.5 & $\mathbf{5}$ & 0.1 & 2 & 0.18 & 0.5 & 0.5 & 0.1 & 0.1 & 1.711 & 2.717 & 1.030 & -0.731 \\
\hline 0.5 & 4 & $\mathbf{0 . 3}$ & 2 & 0.18 & 0.5 & 0.5 & 0.1 & 0.1 & 1.656 & 3.045 & 0.866 & -0.431 \\
\hline 0.5 & 4 & $\mathbf{0 . 5}$ & 2 & 0.18 & 0.5 & 0.5 & 0.1 & 0.1 & 1.664 & 3.207 & 0.872 & -0.422 \\
\hline 0.5 & 4 & 0.1 &. $\mathbf{5}$ & 0.18 & 0.5 & 0.5 & 0.1 & 0.1 & 1.747 & 1.793 & 0.987 & -0.857 \\
\hline 0.5 & 4 & 0.1 & $\mathbf{. 6}$ & 0.18 & 0.5 & 0.5 & 0.1 & 0.1 & 1.771 & 2.086 & 1.103 & -0.845 \\
\hline 0.5 & 4 & 0.1 & .7 & 0.18 & 0.5 & 0.5 & 0.1 & 0.1 & 1.773 & 2.371 & 1.199 & -0.836 \\
\hline 0.5 & 4 & 0.1 & 2 & $\mathbf{0 . 1 5}$ & 0.5 & 0.5 & 0.1 & 0.1 & 1.656 & 1.842 & 0.268 & -0.529 \\
\hline 0.5 & 4 & 0.1 & 2 & $\mathbf{0 . 1 6}$ & 0.5 & 0.5 & 0.1 & 0.1 & 1.663 & 2.291 & 0.276 & -0.517 \\
\hline 0.5 & 4 & 0.1 & 2 & $\mathbf{0 . 1 7}$ & 0.5 & 0.5 & 0.1 & 0.1 & 1.667 & 2.576 & 0.295 & -0.506 \\
\hline 0.5 & 4 & 0.1 & 2 & 0.18 & $\mathbf{0 . 3}$ & 0.5 & 0.1 & 0.1 & 1.704 & 2.576 & 0.676 & -0.283 \\
\hline 0.5 & 4 & 0.1 & 2 & 0.18 & $\mathbf{0 . 4}$ & 0.5 & 0.1 & 0.1 & 1.748 & 2.576 & 0.882 & -0.272 \\
\hline 0.5 & 4 & 0.1 & 2 & 0.18 & $\mathbf{0 . 5}$ & 0.5 & 0.1 & 0.1 & 2.624 & 2.576 & 1.895 & -0.261 \\
\hline 0.5 & 4 & 0.1 & 2 & 0.18 & 0.5 & $\mathbf{0 . 3}$ & 0.1 & 0.1 & 1.624 & 2.576 & 1.006 & -0.625 \\
\hline 0.5 & 4 & 0.1 & 2 & 0.18 & 0.5 & $\mathbf{0 . 4}$ & 0.1 & 0.1 & 1.727 & 2.576 & 1.024 & -0.611 \\
\hline 0.5 & 4 & 0.1 & 2 & 0.18 & 0.5 & 0.5 & $\mathbf{0 . 0 7}$ & 0.1 & 2.637 & 3.832 & 1.743 & -0.198 \\
\hline 0.5 & 4 & 0.1 & 2 & 0.18 & 0.5 & 0.5 & $\mathbf{0 . 0 8}$ & 0.1 & 1.748 & 3.391 & 0.666 & -0.189 \\
\hline 0.5 & 4 & 0.1 & 2 & 0.18 & 0.5 & 0.5 & 0.1 & $\mathbf{0 . 0 7}$ & 1.749 & 2.646 & 1.033 & -0.321 \\
\hline 0.5 & 4 & 0.1 & 2 & 0.18 & 0.5 & 0.5 & 0.1 & $\mathbf{0 . 0 8}$ & 1.739 & 2.625 & 1.018 & -0.306 \\
\hline 0.5 & 4 & 0.1 & 2 & 0.18 & 0.5 & 0.5 & 0.1 & $\mathbf{0 . 0 9}$ & 1.647 & 2.601 & 0.888 & -0.292 \\
\hline
\end{tabular}

When the batch size distribution parameter $(\mathrm{p})$ varies from $0.3 \times 10^{4}$ packets $/ \mathrm{sec}$ to $0.7 \times 10^{4}$ packets $/ \mathrm{sec}$, the transmission rate of first transmitter $\left(\beta_{1}\right)$ increases from 1.656 to 1.779 , the transmission rate of second transmitter $\left(\beta_{2}\right)$ increases from 3.045 to 3.376 and the total optimal cost function increases from 0.866 to 0.914 when other parameters are fixed at $(0.5,4,2,0.18,0.5,0.5,0.1$, 0.1 ) for ( $\mathrm{t}, \mathrm{m}, \alpha, \theta, \mathrm{R}_{1}, \mathrm{R}_{2}, \mathrm{C}_{1}, \mathrm{C}_{2}$ ). As the arrival rate $(\alpha)$ varies from $1.5 \times 10^{4}$ messages $/ \mathrm{sec}$ to $1.7 \times 10^{4}$ messages/sec, the transmission rate of first transmitter $\left(\beta_{1}\right)$ increases from 1.747 to 1.773 , the transmission rate of second transmitter $\left(\beta_{2}\right)$ increases from 1.793 to 2.371 and the total optimal cost function increases from 0.987 to 1.199 when other parameters are fixed at $(0.5,4,0.1,0.18$, $0.5,0.5,0.1,0.1)$ for (t, $\left.m, p, \theta, R_{1}, R_{2}, C_{1}, C_{2}\right)$.
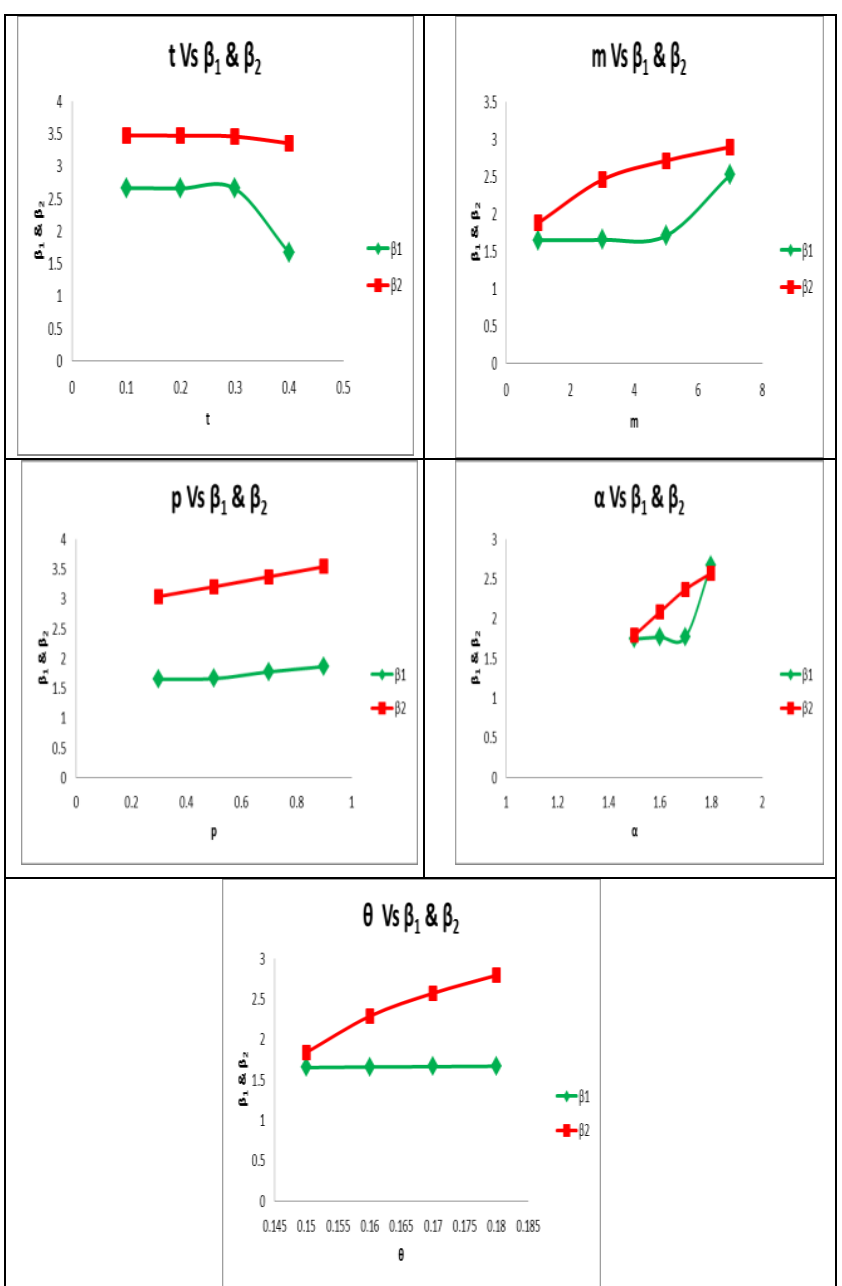

Fig 7: The optimal performance of various parameters

When the forward transmission probability $(\theta)$ varies from 0.15 to 0.17 , the transmission rate of first transmitter $\left(\beta_{1}\right)$ increases from 1.656 to 1.667 , the transmission rate of second transmitter $\left(\beta_{2}\right)$ increases from 1.842 to 2.576 and the total optimal cost function increases from 0.268 to 0.295 when other parameters are fixed at $(0.5,4,0.1,2$, $0.5,0.5,0.1,0.1)$ for ( $\left.t, m, p, \alpha, R_{1}, R_{2}, C_{1}, C_{2}\right)$. When the revenue parameter $\left(\mathrm{R}_{1}\right)$ varies from 0.3 to 0.5 , the transmission rate of first transmitter $\left(\beta_{1}\right)$ increases from 1.704 to 2.624 , the transmission rate of second transmitter $\left(\beta_{2}\right)$ remain unchanged as 2.576 and the total optimal cost function increases from 0.676 to 1.895 when other parameters are fixed at $(0.5,4,0.1,2,0.18,0.5,0.1,0.1)$ for ( $\left.t, m, p, \alpha, \theta, R_{2}, C_{1}, C_{2}\right)$. When the revenue parameter $\left(\mathrm{R}_{2}\right)$ varies from 0.3 to 0.5 , the transmission rate of first transmitter $\left(\beta_{1}\right)$ increases from 1.624 to 1.743 , the transmission rate of second transmitter $\left(\beta_{2}\right)$ remain unchanged as 2.576 and the total optimal cost function increases from 1.006 to 1.028 when other parameters are fixed at $(0.5,4,0.1,2,0.18,0.5,0.1,0.1)$ for $(\mathrm{t}, \mathrm{m}, \mathrm{p}, \alpha, \theta$, $\left.\mathrm{R}_{1}, \mathrm{C}_{1}, \mathrm{C}_{2}\right)$. When the cost parameter $\left(\mathrm{C}_{1}\right)$ varies from 0.07 to 0.09 , the transmission rate of first transmitter $\left(\beta_{1}\right)$ decreases from 2.637 to 1.746 , the transmission rate of second transmitter $\left(\beta_{2}\right)$ decreases from 3.832 to 2.983 and the total optimal cost function decreases from 1.743 to 0.639 when other parameters are fixed at $(0.5,4,0.1,2$, $0.18,0.5,0.5,0.1)$ for ( $t, m, p, \alpha, \theta, R_{1}, R_{2}, C_{2}$ ). When the cost parameter $\left(\mathrm{C}_{2}\right)$ varies from 0.07 to 0.09 , the transmission rate of first transmitter $\left(\beta_{1}\right)$ decreases from 
1.749 to 1.647 , the transmission rate of second transmitter $\left(\beta_{2}\right)$ decreases from 2.646 to 2.601 and the total optimal cost function decreases from 1.033 to 0.888 when other parameters are fixed at $(0.5,4,0.1,2,0.18,0.5,0.5,0.1)$ for (t, $\mathrm{m}, \mathrm{p}, \alpha, \theta, \mathrm{R}_{1}, \mathrm{R}_{2}, \mathrm{C}_{1}$ ).

\section{SENSITIVITY ANALYSIS}

The sensitivity analysis of the Transmission Rate parameters $\beta_{1}{ }^{*}$ and $\beta_{2}{ }^{*}$, and the total cost function $\mathrm{p}^{*}(\mathrm{t})$ are studied with respect to the parameters t, $\mathrm{m}, \mathrm{p}, \alpha, \theta, \mathrm{R}_{1}$, $R_{2}, C_{1}$ and $C_{2}$. Sensitivity analysis of the model is carried out with respect to the parameters t, m, p, $\alpha, \theta, R_{1}, R_{2}, C_{1}$, and $C_{2}$ on the transmission rate of first transmitter $\left(\beta_{1}\right)$ and the transmission rate of second transmitter $\left(\beta_{2}\right)$

The following data has been considered for the sensitivity analysis.

$\mathrm{t}=0.5 \mathrm{sec}, \mathrm{m}=4 \times 10^{4}$ packets $/ \mathrm{sec}, \mathrm{p}=0.1, \alpha=2 \times 10^{4}$ packets/sec, $\theta=0.18$ packets $/ \mathrm{sec}, \mathrm{R}_{1}=0.5, \mathrm{R} 2=0.5, \mathrm{C}_{1}$ $=0.07$ and $\mathrm{C}_{2}=0.07$.

The performance measure of the model is computed by variation of $-15 \%,-10 \%,-5 \%, 0 \%,+5 \%,+10 \%$ and $+15 \%$ on the input parameters $\mathrm{t}, \mathrm{p}, \alpha, \theta, \mathrm{R}_{1}, \mathrm{R}_{2} \mathrm{C}_{1}$ and $\mathrm{C}_{2}$ and $-75 \%,-50 \%,-25 \%, 0 \%,+25 \%,+50 \%$ and $+75 \%$ on the batch size distribution parameter $m$ to retain them as integers. The computed values of the performance measures are given in Table 7.

\begin{tabular}{|c|c|c|c|c|c|c|c|c|}
\hline \multirow{2}{*}{$\begin{array}{l}\text { Para- } \\
\text { meter }\end{array}$} & \multirow{2}{*}{$\begin{array}{r}\text { Performance } \\
\text { Measure }\end{array}$} & \multicolumn{7}{|c|}{$\%$ change in parameters } \\
\hline & & $-15 \%$ & $-10 \%$ & $-5 \%$ & 0 & $+5 \%$ & $+10 \%$ & $+15 \%$ \\
\hline \multirow{3}{*}{$\mathrm{t}=0.5$} & $\beta_{1}$ & 1.701 & 1.765 & 1.835 & 1.909 & 1.991 & 2.082 & 2.188 \\
\hline & $\beta_{2}$ & 1.554 & 1.614 & 1.637 & 1.734 & 1.797 & 1.864 & 1.937 \\
\hline & $\mathrm{R}$ & 2.468 & 2.492 & 2.510 & 2.526 & 2.539 & 2.562 & 2.583 \\
\hline \multirow{3}{*}{$\mathrm{P}=0.1$} & $\beta_{1}$ & 1.553 & 1.601 & 1.663 & 1.670 & 1.675 & 1.683 & 1.781 \\
\hline & $\beta_{2}$ & 1.393 & 1.401 & 1.411 & 1.425 & 1.431 & 1.410 & 1.389 \\
\hline & $\mathrm{R}$ & 1.992 & 2.086 & 2.126 & 2.232 & 2.368 & 2.501 & 2.628 \\
\hline \multirow{3}{*}{$\lambda=2$} & $\beta_{1}$ & 1.604 & 1.632 & 1.664 & 1.683 & 1.775 & 1.781 & 1.787 \\
\hline & $\beta_{2}$ & 1.533 & 1.616 & 1.690 & 1.762 & 1.789 & 1.815 & 1.841 \\
\hline & $\mathrm{R}$ & 2.401 & 2.428 & 2.441 & 2.459 & 2.484 & 2.501 & 2.532 \\
\hline \multirow{3}{*}{$\Theta=0.18$} & $\beta_{1}$ & 1.603 & 1.624 & 1.652 & 1.670 & 1.692 & 1.710 & 1.762 \\
\hline & $\beta_{2}$ & 1.261 & 1.473 & 1.654 & 1.734 & 1.812 & 1.893 & 1.976 \\
\hline & $\mathrm{R}$ & 2.307 & 2.352 & 2.381 & 2.438 & 2.498 & 2.555 & 2.608 \\
\hline \multirow{3}{*}{$\mathrm{R} 1=0.5$} & $\beta_{1}$ & 1.762 & 1.794 & 1.812 & 1.836 & 1.841 & 1.845 & 1.856 \\
\hline & $\beta_{2}$ & 1.767 & 1.793 & 1.819 & 1.845 & 1.870 & 1.895 & 1.920 \\
\hline & $\mathrm{R}$ & 2.135 & 2.164 & 2.198 & 2.220 & 2.259 & 2.281 & 2.304 \\
\hline \multirow{3}{*}{$\mathrm{R} 2=0.5$} & $\beta_{1}$ & 1.516 & 1.542 & 1.569 & 1.584 & 1.592 & 1.612 & 1.632 \\
\hline & $\beta_{2}$ & 1.702 & 1.7119 & 1.731 & 1.745 & 1.766 & 1.783 & 1.801 \\
\hline & $\mathrm{R}$ & 2.228 & 2.253 & 2.281 & 2.301 & 2.365 & 2.384 & 2.401 \\
\hline \multirow{3}{*}{$\mathrm{C} 1=0.4$} & $\beta_{1}$ & 1.542 & 1.569 & 1.582 & 1.591 & 1.598 & 1.613 & 1.628 \\
\hline & $\beta_{2}$ & 1.579 & 1.590 & 1.608 & 1.625 & 1.637 & 1.661 & 1.693 \\
\hline & $\mathrm{R}$ & 1.962 & 1.981 & 2.004 & 2.221 & 2.245 & 2.267 & 2.291 \\
\hline \multirow{3}{*}{$\mathrm{C} 2=0.2$} & $\beta_{1}$ & 1.803 & 1.818 & 1.832 & 1.843 & 1.851 & 1.869 & 1.882 \\
\hline & $\beta_{2}$ & 1.726 & 1.759 & 1.772 & 1.791 & 1.804 & 1.821 & 1.844 \\
\hline & $\mathrm{R}$ & 2.252 & 2.275 & 2.291 & 2.312 & 2.334 & 2.367 & 2.391 \\
\hline \multirow{4}{*}{$\mathrm{m}=4$} & & $-75 \%$ & $-50 \%$ & $-25 \%$ & 0 & $+25 \%$ & $+50 \%$ & $+75 \%$ \\
\hline & $\beta_{1}$ & 1.601 & 1.623 & 1.641 & 1.667 & 1.681 & 1.698 & 1.712 \\
\hline & $\beta_{2}$ & 1.814 & 1.835 & 1.851 & 1.881 & 1.894 & 1.912 & 1.934 \\
\hline & $\mathrm{R}$ & 2.289 & 2.301 & 2.324 & 2.342 & 2.361 & 2.392 & 2.407 \\
\hline
\end{tabular}

The performance measures are highly affected by varying the time (t) and the batch size distribution parameters of arrivals, a time $(\mathrm{t})$ increases to $15 \%$ the average number of packets transmitting through the two buffers increases along with the two transmitters. Similarly, as the arrival rate of messages $(\alpha)$ increases by $15 \%$, the average number of packets transmitted through two transmitter's increases. Over all analysis of the parameters reflects that, dynamic bandwidth allocation strategy for congestion control tremendously reduces the mean delay in communication and improve voice quality by reducing burstness in buffers.

The sensitivity analysis of the Transmission rate parameters $\beta_{1}{ }^{*}$ and $\beta_{2}{ }^{*}$, Arrival rate $\alpha$ and the total cost function $\mathrm{p}^{*}(\mathrm{t})$ are studied with respect to the parameters $\mathrm{t}$, $\mathrm{m}, \mathrm{p}, \theta, \mathrm{R}_{1}, \mathrm{R}_{2}, \mathrm{C}_{1}$ and $\mathrm{C}_{2}$. Sensitivity analysis of the model is performed with respect to the parameters $t, m, p$, $\theta, R_{1}, R_{2}, C_{1}$, and $C_{2}$ on the arrival rate $(\alpha)$, transmission rate of first transmitter $\left(\beta_{1}\right)$ and the transmission rate of second transmitter $\left(\beta_{2}\right)$. The performance measures are highly affected with the variation in time $(\mathrm{t})$ and the batch size distribution parameters of arrivals. As time (t) increases by $15 \%$ the average number of packets transmitting through the two buffers increases along with the two transmitters and the arrival rate of the packets increases. As the batch size distribution parameter $p$ increases to $15 \%$, the average number of packets transmitting through the two buffers increases along with the two transmitters and the arrival rate of the packets increases. Over all analysis of the parameters reflects that dynamic bandwidth allocation strategy for congestion control tremendously reduces the mean delay in communication and improve voice quality by reducing burstness in buffers.

\section{CONCLUSION}

This paper introduces a novel method for performance evaluation and stochastic control of the two node tandem communication system with phase type transmissions. The massages arrive to the communication network are converted into a random number of packets and stored in buffers for forward transmission. The arrival process of the communication network is well characterized by compound binomial Poisson processes such that the bulk arriving nature is induced in the analysis. The system performance measures such as the average content of the buffers, the mean delays in transmission, the throughput of the node are derived explicitly and analysed. It is observed that the arrival distribution parameters and Dynamic Bandwidth Allocation strategy have significant influence on the performance measures of the network. With suitable cost considerations the total cost function and profit rate function are derived, By maximizing the profit rate function of the optimal operating policies of the network are derived and analysed. This optimal policies are much helpful for traffic controllers and service providers to utilize the resources more effectively and efficiently.

\section{REFERENCES}

[1] Baccelli, F. and Massey, W.A. (1988), A transient analysis of the two node Jackson network, Research Report, RR 0852.

[2] Bardeen and Brattain, IEEE Communications Society (2002).

[3] Feldmann A, (2000), Characteristics of TCP connection arrivals, Chapter15, self-similar network traffic and performance evaluation, edited by K.Park, W.Willinger, John Wiley \& Sons Inc.

[4] Gaujal, B. and Hyon, E.(2002), Optimal routing policies in deterministic queues in tandem, Proceedings of Sixth International Workshop on Discrete Event Systems (WODES’02),pp.251-257. 
[5] G.Padmavathi, K.Srinivasa Rao And K.V.V.S.Reddy- (2009), Performance Evaluation of Parallel and Series Communication Network with dynamic bandwidth allocation, CIITInternational journal of Networking and Communication Engineering.Vol.1,No7, pp.410-421.

[6] Kin K. Leung (2002), Load dependent service queues with application to congestion control in broadband networks, Performance Evaluation, Vol.50, Issue 1-4, pp. 27-40.

[7] K.Nageswara Rao, K.Srinivasa Rao, P.Srinivasa Rao - (2010), A tandem Communication network with DBA and modified phase type Transmission having bulk arrivals in International journal of Computer Science issues, Vol7, No3. pp18-26

[8] Kuda Nageswarara Rao, K.Srinivasa Rao and P.Srinivasa Rao-(2011)- Transient Analysis of a Tandem Communication network with dynamic bandwidth allocation having two stage direct bulk arrivals, International Journal of Computer Applications, Vol.13, No.7, pp.14-22.

[9] K.Srinivasa Rao, P.Suresh Varma and Y.Srinivas (2008), Interdependent Queuing Model with start-up delay, Journal of Statistical Theory and Applications, Vol. 7, No. 2 pp. 219-228.

[10] Moshe Sidi (1987), Tandem packet radio queuing system, IEEE Transactions on Communications, Vol.COM-35, No.2.
[11] Murali Krishna P, Gadre V M, Desai U B (2003), Multi fractal based network traffic modelling, Kluwer Academic publishers, ISBN.1-4020-7566-9.

[12] Parthasarathy, P.R.and Selvraju, N. (2001), Transient analysis of a Queue where potential customers are discouraged by Queue length. Mathematical Problems in Discrete distribution and process to model self-similar traffic, $9^{\text {th }}$ IEEE international conference on Telecommunication- CONTEL2007, Zagred b Croatia, pp.167-171 Engineering,Vol.7, pp.433-454.

[13] P.Suresh Varma and K.Srinivasa Rao (2007), A Communication network with load dependent transmission, International Journal of Mathematical Sciences, Vol.6, No.2, pp.199-210.

[14] Srinivasa Rao K, Vasanta, M.R., and Vijaya Kumar, C.V.R.S.,(2000), on an interdependent Communication Network, OpsearchVol.37, No.2, pp134-143.

[15] Sriram, K. (1993), Methodologies for bandwidth allocation, transmission scheduling and congestion avoidance in broadband ATM networks, Computer Network, ISDN System, J.26, pp:43-59.

[16] Stanislav Angelov, Sanjeev Khanna and Keshav Kunal (2009), The network as a storage device: Dynamic routing with bounded buffers, Algorithmica, Vol.55, No.1, pp 71-94. 